\title{
Expression Signature and Role of miR- 30d-5p in Non-Small Cell Lung Cancer: a Comprehensive Study Based on in Silico Analysis of Public Databases and in Vitro Experiments
}

\author{
$\mathrm{Li} \mathrm{Gao}^{\mathrm{a}}$ Rong-quan He $\mathrm{H}^{\mathrm{b}}$ Hua-yu Wuc Tong-tong Zhang ${ }^{\mathrm{a}}$ Hai-wei Liang ${ }^{\mathrm{a}}$ \\ Zhi-hua Ye $^{\mathrm{a}}$ Zu-yun Lia Ting-ting Xie ${ }^{\mathrm{a}}$ Qi Shia Jie Ma ${ }^{\mathrm{b}}$ Xiao-hua Hu \\ Gang Chen ${ }^{\mathrm{a}}$ \\ aDepartment of Pathology, First Affiliated Hospital of Guangxi Medical University, Nanning, \\ bDepartment of Medical Oncology, First Affiliated Hospital of Guangxi Medical University, Nanning, \\ 'Department of cell biology\&genetics, Guangxi Medical University, Nanning, China
}

\section{Key Words}

miR-30d-5p • Real-time quantitative polymerase chain reaction • Gene expression omnibus • Meta-analysis • The cancer genome atlas • Target genes

\begin{abstract}
Background/Aims: The purpose of this study was to probe the clinico-pathological significance and the underlying mechanism of miR-30d-5p expression in non-small cell lung cancer (NSCLC). Methods: We initially examined the level of miR-30d-5p expression in NSCLC and non-cancer tissues using RT-qPCR. Then, a series of validation analyses including a meta-analysis of data from microarray chips in Gene Expression Omnibus (GEO), data mining of the cancer genome atlas (TCGA) and an integrated meta-analysis incorporating GEO microarray chips, TCGA data, in-house RT-qPCR and literature studies were performed to examine the clinico-pathological value of miR-30d-5p expression in NSCLC. In vitro experiments were further conducted to investigate the impact of miR-30d-5p on NSCLC cell growth. The molecular mechanism by which miR-30d-5p regulates the pathogenesis of NSCLC was probed through a bioinformatics analysis of its target genes. Moreover, dual luciferase reporter assay was conducted to verify the targeting regulatory relationship between miR-30d-5p and CCNE2. Results: Based on results from RT-qPCR, GEO meta-analysis, TCGA data mining and the integrated meta-analysis incorporating GEO microarray chips, TCGA data, in-house RT-qPCR and literature studies, miR$30 \mathrm{~d}-5 \mathrm{p}$ expression was decreased in NSCLC tissues, and patients with NSCLC who presented with lower miR-30d-5p expression tended to display an advanced clinical progression.

L. Gao and R.-q. He contributed equally to this work.

\footnotetext{
Prof. Dr. Xiao-Hua Hu and Prof. Dr. Gang Chen

Department of Medical Oncology and Pathology, First Affiliated Hospital of Guangxi Medical University 6 Shuangyong Road, Nanning 530021, Guangxi Zhuang Autonomous Region (China)
}

Tel. (+86) 0771-5312980, Fax (+86) 0771-5312980, E-Mail gxmuhxh@163.com; chengang@gxmu.edu.cn
\end{abstract}


Significant pathways including the Mucin type O-glycan biosynthesis pathway, cell cycle pathway and cysteine and methionine metabolism pathway (all $\mathrm{P}<0.05$ ) revealed potential roles of the target genes of miR-30d-5p in the oncogenesis of NSCLC. Results from in vitro experiments indicated that miR-30d-5p could attenuate proliferation and viability of NSCLC cells. Among the 12 identified hub genes, nine genes including E2F3, CCNE2, SKP2, CDK6, TFDP1, LDHA, GOT2, DNMT3B and ST6GALNAC1 were validated by Pearson's correlation test and the human protein atlas (HPA) database as targets of miR-30d-5p with higher probability. Specifically, dual luciferase reporter assay confirmed that CCNE2 was directly targeted by miR$30 \mathrm{~d}-5 \mathrm{p}$. Conclusion: In summary, miR-30d-5p expression is decreased in NSCLC, and it might play the role as tumor suppressor in NSCLC by regulating target genes.

(C) 2018 The Author(s)

Published by S. Karger AG, Basel

\section{Introduction}

Lung cancer (LC) is included in the list of the most widespread human malignancies. The incidence and mortality of LC rank first in malignant tumors among males and second in malignant tumors among females [1-4]. LC is divided into two subtypes: small cell lung cancer (SCLC) and non-small cell lung cancer (NSCLC). NSCLC comprises lung squamous cell carcinoma (LUSC), lung adenocarcinoma (LUAD) and large cell lung cancer (LCLC), and represents $85 \%$ of all LC cases [5-8]. Despite recent diagnostic and therapeutic innovations, the overall 5-year survival rate of patients with NSCLC is only 10\% [9], which prompted us to explore the molecular mechanism underlying the initiation and development of NSCLC and to identify novel targets for enhancing the diagnosis and treatment of NSCLC.

MiRNAs are a class of short, noncoding RNAs of 17-25 nucleotides in length [10]. More than 1000 miRNAs have been identified in humans and are predicted to modulate the expression of at least $60 \%$ of protein-coding genes at the transcriptional level [11-13]. By repressing target genes, miRNAs play key roles in various biological events in tumors, such as cell proliferation, differentiation, apoptosis and tumor invasion [14-18]. Therefore, miRNAs are implicated as promising diagnostic and prognostic biomarkers for human cancers, including pancreatic cancer, bladder cancer, colorectal cancer and gastric cancer [13, 19-21].

Previous studies have reported the involvement of miR-30d-5p in the carcinogenesis of several cancers, such as prostate cancer, colon cancer and conjunctival malignant melanoma [22-24]. Notably, miR-30d-5p expression is down-regulated in NSCLC tissues, and it exerts significant suppressive effects on the tumor growth, cell cycle progression, and motility of NSCLC cells [25]. However, the precise role of miR-30d-5p in NSCLC has not yet been clarified.

This study was designed to comprehensively evaluate the clinico-pathological value of miR-30d-5p in NSCLC through a combined method of real-time quantitative polymerase chain reaction (RT-qPCR), Gene Expression Omnibus (GEO) meta-analysis, the cancer genome atlas (TCGA) data mining, an integrative meta-analysis and a literature metaanalysis. We also endeavored to shed light on the mechanism by which miR-30d-5p regulates the pathogenesis of NSCLC by analyzing the influence of miR-30d-5p on cell growth and the interaction networks of its target genes.

\section{Materials and Methods}

\section{Clinical NSCLC tissue samples}

One hundred and twenty-five formalin-fixed, paraffin-embedded (FFPE) NSCLC tissues and the corresponding adjacent non-cancer lung tissues were collected from Department of Pathology, The First Affiliated Hospital of Guangxi Medical University (Nanning, Guangxi, China) from January 2012 to February 2014. The research protocol for this study was authorized by the ethics committee of the First Affiliated Hospital of Guangxi Medical University. All participants provided informed consent before enrollment in the study. All NSCLC cases were independently diagnosed and confirmed by two pathologists (Zu-yun Li 


\section{Cellular Physiology Cell Physiol Biochem 2018;50:1964-1987

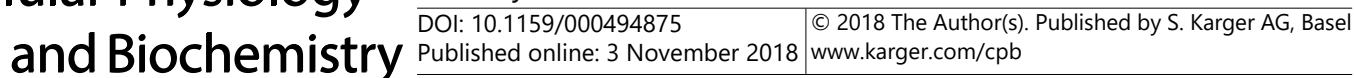

and Gang Chen). The clinico-pathological parameters of all enrolled patients with NSCLC are summarized in Table 1. Criteria for age and pathological grading of patients with NSCLC were derived from the study by Chen WJ et al. [26]. We divided patients into categories based on tumor size and TNM stage according to the IASLC 2009 criteria [27].

\section{RT-qPCR}

The miRNeasy Kit (QIAGEN, KJVenlo, The Netherlands) was utilized to extract RNA from FFPE tissues, as described in previous studies [28-30]. A NanoDrop 2000 (Wilmington, DE, USA) was employed to determine the concentration and purity of the extracted RNA. MiR-191 and miR-103 were used as the housekeeping miRNAs for the detection of miR-30d-5p expression. The primers for miR-191, miR-103 and miR-30d-5p were provided by TaqMan ${ }^{\circledR}$ MicroRNA Assays. The sequences of miR191, miR-103 and miR-30d-5p are: miR-191 (Applied Biosystems, 4427975-000490): CAACGGAAUCCCAAAAGCAGCU; miR-103 (Applied Biosystems, 4427975-000439):AG CAGCAUUGUACAGGGCUAUGA; and miR30d-5p (Applied Biosystems, 4427975000420): UGUAAACAUCCCCGACUGGAAG. The reverse primers were also used in the step of reverse transcription with TaqMan® MicroRNA Reverse Transcription Kit (4366596, Applied Biosystems, Life Technologies Grand Island, NY 14072 USA) in a total volume of $10 \mu \mathrm{l}$. Real-time qPCR for miRNAs was performed with the Applied Biosystems PCR7900 instrument, according to the manufacturer's instructions. The expression level of miR$30 \mathrm{~d}-5 \mathrm{p}$ was calculated using $2-\Delta \mathrm{cq}$ method.

Statistical analyses for RT-qPCR were performed using SPSS 22.0. Levels of miR-30d-5p expression obtained from RT-qPCR analyses are presented as $\mathrm{M} \pm \mathrm{SD}$. Student's paired test was conducted to compare miR-30d-5p expression in NSCLC and matched non-cancer tissues using RT-qPCR. The distribution of miR-30d-5p expression in other clinico-pathological groups that contained two variables was calculated using Student's unpaired t test. One-way analysis of variance (ANOVA) was applied to compare miR-30d-5p expression between groups containing three or more variables.

Table 1. The relationship between miR-30d-5p expression and clinico-pathological parameters of NSCLC from RT-qPCR data. Note: N: number; M: mean; SD: standard deviation. a:paired sample's t test was performed to compare miR30d-5p expression between NSCLC and non-cancer tissues. Independent sample's t test was performed to evaluate the relationship between miR-30d-5p expression and the clinico-pathological parameters of NSCLC. *: One-way ANOVA was performed to assess the distribution difference of miR$30 \mathrm{~d}-5 \mathrm{p}$ in three or more groups of clinico-pathological parameters

\begin{tabular}{|c|c|c|c|c|c|}
\hline \multirow[t]{2}{*}{ Clinical variable } & \multirow[t]{2}{*}{$\mathrm{N}$} & & \multicolumn{3}{|c|}{ MiR-30d-5p relevant expression } \\
\hline & & & $\mathrm{M} \pm \mathrm{SD}$ & $\mathrm{t}$ & $\mathrm{P}$ \\
\hline \multirow[t]{4}{*}{ Tissue type } & NSCLC & 12 & $4.169 \pm 2.51$ & & \\
\hline & & 5 & 7 & $-4.325^{a}$ & $<0.001$ \\
\hline & Non-cancer & 12 & $5.652 \pm 3.18$ & & \\
\hline & & 5 & 7 & & \\
\hline \multirow[t]{4}{*}{ Age (years) } & $<60$ & 57 & $3.702 \pm 2.13$ & & \\
\hline & & & 8 & & \\
\hline & $\geq 60$ & 68 & & -1.965 & 0.052 \\
\hline & & & 0 & & \\
\hline \multirow[t]{4}{*}{ Gender } & Female & 50 & $4.882 \pm 2.51$ & & \\
\hline & & & 6 & & \\
\hline & Male & 75 & & -2.647 & 0.009 \\
\hline & & & 8 & & \\
\hline \multirow[t]{4}{*}{ Smoke } & No & 38 & $4.147 \pm 2.61$ & & \\
\hline & & & 4 & & \\
\hline & Yes & 30 & & 0.834 & 0.407 \\
\hline & & & 0 & & \\
\hline \multirow[t]{4}{*}{ Tumor size $(\mathrm{cm})$} & $\leq 3$ & 60 & $4.547 \pm 2.66$ & & \\
\hline & & & 3 & & \\
\hline & $>3$ & 65 & & 1.621 & 0.108 \\
\hline & & & 1 & & \\
\hline \multirow[t]{4}{*}{ Lymph node metastasis } & No & 56 & $4.803 \pm 2.73$ & & \\
\hline & & & 1 & & \\
\hline & Yes & 69 & & 2.594 & 0.011 \\
\hline & & & 8 & & \\
\hline \multirow[t]{4}{*}{ Vascular invasion } & No & 90 & $4.418 \pm 2.65$ & 2.023 & 0.046 \\
\hline & & & 7 & & \\
\hline & Yes & 35 & $3.529 \pm 2.00$ & & \\
\hline & & & 7 & & \\
\hline \multirow[t]{4}{*}{ TNM } & I-II & 54 & $4.736 \pm 2.562 .232$ & 0.027 & \\
\hline & & & 2 & & \\
\hline & III-IV & 71 & $3.738 \pm 2.41$ & & \\
\hline & & & 1 & & \\
\hline \multirow[t]{6}{*}{ Pathological grading } & I & 17 & $3.835 \pm 2.38$ & & \\
\hline & & & 0 & & \\
\hline & U & 78 & $4.369 \pm 2.530 .648^{*}$ & * 0.525 & \\
\hline & 11 & 10 & 4 & & \\
\hline & III & 30 & $3.840 \pm 2.57$ & & \\
\hline & & & 4 & & \\
\hline Pathological & LUAD & 10 & $4.285 \pm 2.44$ & & \\
\hline \multirow[t]{4}{*}{ classification } & & 1 & 7 & & \\
\hline & LUSC & 23 & $3.759 \pm 2.83$ & $0.817^{*}$ & 0.444 \\
\hline & & & 2 & & \\
\hline & LCLC & 1 & 1.900 & & \\
\hline
\end{tabular}




\section{Cellular Physiology Cell Physiol Biochem 2018;50:1964-1987 \begin{tabular}{l|l|l} 
and Biochemistry Published onlıne: 3 November 2018 & $\begin{array}{l}\text { (c) } 2018 \text { The Author(s). Published by S. Karger AG, Basel } \\
\text { www.karger.com/cpb }\end{array}$ \\
\hline
\end{tabular}}

\section{GEO meta-analysis for miR-30d-5p expression in NSCLC tissues}

We searched microarray chips relevant to miR-30d-5p expression in NSCLC published up to August 4th, 2018 in the GEO database (http://www.ncbi.nlm.nih.gov/geo/). The strategy designed to search microarray chips was: (lung OR pulmonary OR respiratory OR bronchi OR bronchioles OR alveoli OR pneumocytes OR "air way") AND (cancer OR carcinoma OR tumor OR neoplas* OR malignan* OR adenocarcinoma) AND (MicroRNA OR miRNA OR “Micro RNA" OR “Small Temporal RNA" OR “non-coding RNA" OR ncRNA OR "small RNA"). Microarray chips that met the following criteria were included in the GEO meta-analysis: (1) the species used for the experiments was human (2) the miR-30d-5p expression level in NSCLC tissues and noncancer tissues was detected using the microarray chip.

We extracted the following information from the included GSE datasets to pool the standard mean difference (SMDs): GSE ID, first author, publication year, country, experimental type, sample type, platform, number $(\mathrm{N})$ of cases in cancer group, mean (M) \pm standard deviation (SD) of miR-30d-5p expression in the cancer group, $\mathrm{N}$ of cases in the non-cancer group, and $\mathrm{M} \pm \mathrm{SD}$ of miR-30d-5p expression in the non-cancer group. True positivity (TP), false positivity (FP), false negativity (FN) and true negativity (TN) for each GSE dataset were calculated based on the maximum Youden index and the corresponding cut-off value from the receiver operating characteristics (ROC) curve for each GSE dataset using SPSS v 22.0 (SPSS, Chicago, IL, USA).

We calculated SMD with 95\% confidence interval $(95 \% \mathrm{CI})$ and constructed summarized receiver operating characteristics (SROC) curves following the methods in previous studies [31].

Validation of miR-30d-5p expression in NSCLC using miRNA-sequencing data from TCGA

We extracted IlluminaHiSeq miRNA-sequencing data for miR-30d-5p in 450 LUAD and 336 LUSC tissues from TCGA database with the aid of online tool: Xena Public Data Hubs (https://xena.ucsc.edu/ public-hubs/) to evaluate miR-30d-5p expression in 786 NSCLC and 89 normal tissues. The expression difference of miR-30d-5p between NSCLC and normal tissues was calculated using Student's unpaired t test in SPSS 22.0.

The integrative meta-analysis incorporating GEO microarray chips, TCGA data, in-house RT-qPCR and literature studies

Apart from our in-house RT-qPCR data and miR-30d-5p expression data from the above public databases, we also searched literature evidence of miR-30d-5p expression between NSCLC and non-cancer tissues in the following literatue databases: PubMed, Embase, Web of Science, Wiley online library, Springerlink, Chinese National Knowledge Infrastructure, Chinese Biomedical Database, Chinese VIP and Wan Fang database. Searching strategies for literature databases were (cancer OR carcinoma OR adenocarcinoma OR tumour OR tumor OR malignanc* OR neoplas*) AND (lung OR pulmonary OR respiratory OR respiration OR aspiration OR bronchi OR bronchioles OR alveoli OR pneumocytes OR "air way") AND (miR-30d OR miRNA30d OR microRNA-30d OR miR30d OR miRNA30d OR microRNA30d OR "miR 30d" OR "miRNA 30d" OR "microRNA 30d" OR miR-30d-5p OR miRNA-30d-5p OR microRNA-30d-5p). Literature studies published before August 4th, 2018 that provided the detailed miR-30d-5p expression value in NSCLC and non-cancer tissues $(\mathrm{M} \pm \mathrm{SD}$ ) were included. We collected all expression data for miR-30d-5p in NSCLC and non-cancer tissues from RT-qPCR, GEO microarray chips, TCGA and literature studies to conduct an integrative metaanalysis and achieve an overall assessment of the differential expression of miR-30d-5p in NSCLC and noncancer tissues. The SMD was pooled from all studies to determine the expression level of miR-30d-5p in NSCLC. Pooled sensitivity (SEN), specificity (SPE), positive likelihood ratio (PLR), and negative likelihood ratio (NLR) values and the SROC curve for the integrated meta-anlaysis were calculated to examine the power of miR-30d-5p expression to discriminate NSCLC from non-cancer tissues.

\section{The prognostic significance of miR-30d-5p expression for NSCLC}

To appraise whether miR-30d-5p can be applied in plausible clinical usage for NSCLC, we also need to evaluate the prognostic significance of miR30d-5p in NSCLC. Therefore, survival analysis for the in-house RT-qPCR data and a prognostic meta-analysis of miR-30d-5p were conducted. All patient samples for RTqPCR were divided into groups of low or high miR-30d-5p expression according to the average expression level of miR-30d-5p expression and Kaplan-Meier survival curves were plotted and a log-rank test was 


\section{Cellular Physiology Cell Physiol Biochem 2018;50:1964-1987 \\ \begin{tabular}{l|l|l} 
and Biochemistry Published online: 3 November 2018 & $\begin{array}{l}\text { ○ } 2018 \text { The Author(s). Published by S. Karger AG, Basel } \\
\text { www.karger.com/cpb }\end{array}$ \\
\hline
\end{tabular}}

Gao et al.: miR-30d-5p: Expression Signature and Tumor Suppressive Role in NSCLC

performed to analyze the impact of miR-30d-5p expression on the survival of patients with NSCLC. P $<0.05$ was regarded as statistically significant. As for the prognostic meta-analysis, we systematically searched in public databases such as PubMed, Embase, Web of Science, Wiley online library, Springerlink, Chinese National Knowledge Infrastructure, Chinese Biomedical Database, Chinese VIP and Wan Fang database to select qualified studies published before August $4^{\text {th }}, 2018$ for inclusion in the meta-analysis. Searching strategies for prognostic meta-anlaysis were designed the same as literature searching for miR-30d-5p expression in NSCLC tissues. The inclusion criteria were: (1) patients diagnosed with NSCLC, (2) the study provided hazard ratio (HRs) and $95 \%$ CIs or relevant data from which HRs and 95\% CIs could be calculated, and (3) studies were written in English or Chinese. The exclusion criteria were: (1) studies that performed experiments using cell lines or human xenografts, (2) studies published as letters, case reports, reviews or conference reports, and (3) studies did not provide HRs and 95\% CIs or data from which these values could be calculated.

We extracted the following information from the included studies: name of the first author, publication year, country, sample size, cut-off value, method, survival type, HR, lower limit (LL), upper limit (UL) and sample type. When HRs and 95\% CIs were not directly reported in the study, we calculated HRs and 95\% CIs from Kaplan-Meier curves using the methods described by Tierney et al. [32]. Statistical analyses used in the meta-analysis were described in a previous study [33].

In vitro effect of miR-30d-5p on the biological process of NSCLC cells

Five human NSCLC cell lines: A-549, H292, H460, H1299 and PC9 were purchased from American Type Culture Collection (ATCC) and were cultured in Dulbecco's modified Eagle's medium (DMEM) (Gibco, USA) supplemented with $10 \%$ fetal bovine serum and penicillin-streptomycin at $37^{\circ} \mathrm{C}$ under the condition of 5\% CO2 humidified atmosphere. Each of the in vitro experiments was performed three times. Before transfection, NSCLC cells were plated in 96-well plates at $2.5 \times 10^{3}$ cells per well and maintained at $37^{\circ} \mathrm{C}$ for $24 \mathrm{~h}$. Blank control, negative mimic control, miR-30d-5p mimic, negative inhibitor control and miR30d-5p inhibitor (Ambion) were transfected in NSCLC cell lines at a final concentration of $60 \mathrm{nmol} / \mathrm{L}$ with Lipofectamine 2000 following the manufacturer's instructions. The concentration for transfections was determined based on previous studies [28,34]. MiR-30d-5p expression was detected with RT-qPCR in Applied Biosystems PCR7900 system as described previously [29, 30, 35, 36].

The impact of miR-30d-5p on the proliferation and viability of NSCLC cells was measured by fluorometric resorufin viability assays and MTT assays, as has been described in previous studies $[29,30]$. The statistical analysis was carried out in SPSS v 22.0. All data were expressed in the form of M \pm SD. Twoway analysis of variance (ANOVA) and Bonferroni post-tests were used for the comparisons among groups. We defined a $\mathrm{P}<0.05$ as statistically significant.

\section{Bioinformatics analysis of miR-30d-5p target genes}

We utilized miRWalk2.0, an online prediction website that integrates the predictions from 12 prediction databases: miRanda, miRDB, miRWalk, MicroT4, miRMap, RNAhybrid, miRNAMap, PITA, miRBridge, PICTAR2, RNA22 and TargetScan. After the duplicates were removed, the frequency of each gene in the prediction list was counted. Only genes that were simultaneously predicted by at least six databases were screened in subsequent analyses.

In addition to the online prediction software, we also predicted the target genes of miR-30d-5p in LUAD and LUSC by collecting significantly differentially expressed genes (DEGs) from the TCGA. DEGs from TCGA were processed using EdgeR package and DEGs with an false discovery rate (FDR) of less than 0.05 were identified as possible target genes of miR-30d-5p. The final candidate target genes of miR-30d-5p were generated from the intersection of selected target genes from the online prediction software and DEGs in the TCGA database.

The gene ontology (GO) analysis that appraised the enrichment of target genes in biological process (BP), cellular component (CC) and molecular function (MF) as well as the Kyoto Encyclopedia of Genes and Genomes (KEGG) pathway analysis that enumerated significant pathways correlated with the target genes of miR-30d-5p were performed in Database for Annotation, Visualization and Integrated Discovery (DAVID) to investigate the functions of the target genes in NSCLC. Only GO terms and KEGG pathways with a $P$ value $<0.05$ were regarded as statistically significant. Three dot plots illustrating the enrichment of target genes in BP, CC and MF were drawn using R package: cluster profiler. Moreover, The Search Tool for the 


\section{Cellular Physiology Cell Physiol Biochem 2018;50:1964-1987 and Biochemistry \begin{tabular}{l|l} 
DOI: 10.1159/000494875 2018 The Author(s). Published by S. Karger AG, Basel \\
(c)
\end{tabular}

Retrieval of Interacting Genes (STRING) and Cytoscape v3.4.0 were collaboratively employed to build the protein-protein interaction (PPI) network for target genes in key KEGG pathways. Hub genes considered to play important roles in the interaction networks of target genes were filtered by the degree of connectivity between nodes in the PPI network.

We conducted disease ontology (DO) analysis using R package: cluster profiler to explore the assembly of target genes involved in human diseases. We identified those DO terms with both P and Q values $<0.05$ as diseases in which target genes were significantly clustered.

\section{Verification of genes in key KEGG pathways as direct targets of miR-30d-5p}

We downloaded the expression profiles of all component genes in key KEGG pathways from the TCGA database and performed Pearson's correlation test using GraphPad Prism software v 5 to further validate the regulatory relationships between target genes in key KEGG pathways and miR-30d-5p. Moreover, immunohistochemical staining for these genes in NSCLC and normal lung tissues was retrieved from the human protein atlas (HPA) database to compare the expression pattern of genes from key KEGG pathways in NSCLC and normal tissues.

Dual luciferase reporter assay was performed to verify whether CCNE2 was directly targeted by miR-30d-5p. The 3'UTR of CCNE2 containing putative seed regions of miR-30d-5p were amplified by PCR and inserted into the psiCHECK-2 Luciferase Reporter Vector (Promega, USA) at the Xhol site to construct psiCHECK-CCNE2 3'-UTR. The miR-30d-5p binding site of the 3'UTR of CCNE2 was mutated to generate psiCHECK-CCNE2-mut 3' UTRs. HEK-293 T cells $\left(10^{5}\right.$ per well) were grown in 24-well plates until a cell density of 70-80\%. The cells were co-transfected with 20pmol miR-30d-5p mimic (GenePharma, Shanghai, China), normal control (NC) and 500ng reporter vector of psiCHECK-CCNE2 3'UTRs or psiCHECK-CCNE2mut 3' UTRs. After $27 \mathrm{~h}$ of incubation, the ratios between renilla and firefly luciferase activity were estimated by Dual Luciferase Assay (Promega, USA) according to the manufacturer's protocol. All the experiments were performed in triplicate.

\section{Results}

Analysis of the clinico-pathological value of miR-30d-5p expression in NSCLC using RTqPCR

According to the statistical analysis of RT-qPCR data, miR-30d-5p expression was significantly down-regulated in NSCLC tissues compared with non-cancer tissues (Table 1) (Fig. 1A). Additionally, higher miR-30d-5p expression was detected in female patients than in male patients (Table 1). Regarding the distribution of miR-30d-5p expression in patients divided into other groups based on the clinic-pathological features, patients with NSCLC who were negative for lymph node metastasis, vascular invasion and TNM stage (I-II) presented higher miR-30d-5p expression than the control groups (Table 1).

Fig. 1. The notable down-expression of miR-30d-5p in NSCLC from RT-qPCR and TCGA database. A: Scatter plot for RTqPCR data showed that miR-30d-5p expression was significantly lower in NSCLC tissues (4.169
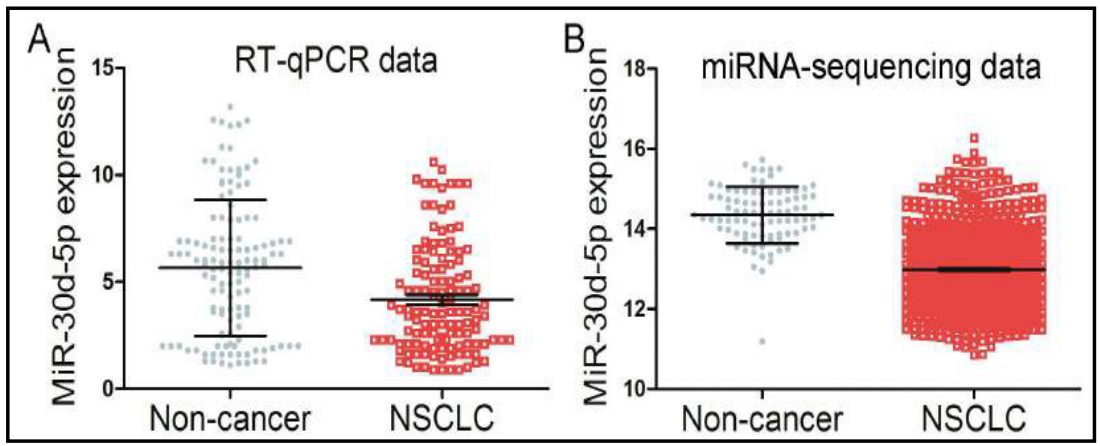
\pm 2.517 ) than in noncancer tissues $(5.652 \pm 3.187)(\mathrm{P}<0.001)$. B: Scatter plot for miRNA-sequencing data from TCGA database also revealed that miR-30d-5p expression was significantly lower in NSCLC tissues $(12.982 \pm 0.968)$ than in non-cancer tissues $(14.348 \pm 0.709)(\mathrm{P}<0.001)$. 


\section{Cellular Physiology and Biochemistry \begin{tabular}{l|l} 
DOI: 10.1159/000494875 & $\begin{array}{l}\text { ( ) 2018 The Author(s). Published by S. Karger AG, Basel } \\
\text { www.karger.com/cpb }\end{array}$
\end{tabular} \\ Gao et al.: miR-30d-5p: Expression Signature and Tumor Suppressive Role in NSCLC}

Table 2. Basic information of all included GSE datasets. Note: N: number; M: mean; SD: standard deviation. Because there were no citations for GSE93300 [64], GSE46729 [69], GSE19945 [75] and GSE74190 [81], URLs of these GSE datasets were provided in the reference lists

\begin{tabular}{|c|c|c|c|c|c|c|c|c|c|c|}
\hline GSE ID & cancer $\mathrm{n}$ & cancer $\mathrm{m}$ & cancer sd & non-cancer $\mathrm{n}$ & non-cancer $\mathrm{m}$ & non-cancer sd & Reference number & Experiment type & Sample type & Platform \\
\hline GSE93300 & 9 & -2.30841 & 2.970626 & 4 & 1.752519 & 1.03737 & {$[64]$} & Non-coding RNA profiling by array & plasma & GPL21576 \\
\hline GSE17681 & 17 & 12.37670335 & 0.606220615 & 19 & 11.99364547 & 0.590107404 & [65] & Non-coding RNA profiling by array & plasma & GPL9040 \\
\hline GSE27486 & 22 & 1.959324922 & 0.448568075 & 23 & 2.053458288 & 0.345334981 & [66] & Non-coding RNA profiling by array & plasma & GPL11432 \\
\hline GSE31568 & 32 & 12.7595809 & 0.491934953 & 70 & 12.78393053 & 0.682875266 & [67] & Non-coding RNA profiling by array & plasma & GPL9040 \\
\hline GSE40738 & 81 & 2.44679994 & 0.290376708 & 56 & 2.366408758 & 0.27424126 & [68] & Non-coding RNA profiling by array & plasma & GPL16016 \\
\hline GSE46729 & 24 & 2.153528599 & 0.093795613 & 24 & 2.163538793 & 0.121159742 & [69] & Non-coding RNA profiling by array & plasma & GPL8786 \\
\hline GSE61741 & 72 & 12.60295617 & 0.587398748 & 94 & 12.34876836 & 0.670511937 & [70] & Non-coding RNA profiling by array & plasma & GPL9040 \\
\hline GSE68951 & 26 & 2.803391767 & 0.099182898 & 12 & 2.79171 & 0.076469 & [71] & Non-coding RNA profiling by array & plasma & GPL16770 \\
\hline GSE16512 & 3 & -2.11902 & 0.951301 & 14 & -2.48575 & 4.248141 & [72] & Non-coding RNA profiling by array & plasma & GPL8686 \\
\hline GSE15008 & 187 & 14.98176149 & 0.863786307 & 188 & 15.78249 & 0.494637 & [73] & Non-coding RNA profiling by array & tissue & GPL8176 \\
\hline GSE16025 & 61 & 8.684519672 & 0.596164003 & 10 & 9.23092 & 1.190293606 & [74] & Non-coding RNA profiling by array & tissue & GPL5106 \\
\hline GSE19945 & 20 & 2.15724 & 0.318845 & 8 & 2.601904 & 0.13709 & [75] & Non-coding RNA profiling by array & tissue & GPL9948 \\
\hline GSE25508 & 24 & 8.648466159 & 1.071802293 & 24 & 9.830976687 & 0.626059957 & [42] & Non-coding RNA profiling by array & tissue & GPL7731 \\
\hline GSE47525 & 18 & 2.102482 & 0.241919 & 14 & 2.562352 & 0.118179 & [76] & Non-coding RNA profiling by array & tissue & GPL17222 \\
\hline GSE48414 & 154 & 0.069243072 & 0.961232617 & 20 & 0.096211547 & 0.937891538 & [77] & Non-coding RNA profiling by array & tissue & GPL16770 \\
\hline GSE51853 & 124 & 1.418157 & 0.467241 & 5 & 1.996553 & 0.111478 & [78] & Non-coding RNA profiling by array & tissue & GPL7341 \\
\hline GSE63805 & 32 & 8.494284 & 0.841674 & 30 & 9.761643 & 0.471141 & [79] & Other & tissue & GPL18410 \\
\hline GSE72526 & 67 & 2.916032557 & 1.617971363 & 18 & 3.479023139 & 0.080328572 & [80] & Non-coding RNA profiling by array & tissue & GPL20275 \\
\hline GSE74190 & 66 & 2.88745123 & 0.196403106 & 44 & 3.083114395 & 0.064810892 & [81] & Non-coding RNA profiling by array & tissue & GPL19622 \\
\hline GSE77380 & 3 & 7.626039 & 1.251118 & 12 & 9.311395 & 0.681205 & [82] & Non-coding RNA profiling by array & tissue & GPL16770 \\
\hline GSE2564 & 14 & 6.356429 & 0.826723 & 4 & 7.5675 & 0.606101 & [83] & Non-coding RNA profiling by array & tissue & GPL1986 \\
\hline GSE29248 & 6 & 13.88282993 & 0.431108514 & 6 & 14.09052748 & 0.374588361 & [84] & Non-coding RNA profiling by array & tissue & GPL8179 \\
\hline GSE56036 & 29 & 9.645160926 & 0.977831077 & 29 & 11.60142125 & 0.511031308 & [85] & Non-coding RNA profiling by array & tissue & GPL15446 \\
\hline
\end{tabular}

Meta-analysis of GSE datasets for miR-30d-5p expression in NSCLC tissues

Our search of the GEO database yielded 340 GSE datasets. After reviewing the titles and abstracts using all microarray chips, we eliminated 256 GSE datasets. Eventually, 23 GSE datasets containing 1098 NSCLC cases and 728 non-cancer cases were screened as eligible microarray chips for further analysis based on the selection criteria. Basic information and data from the included GSE datasets are summarized in Tables 2 and 3. The expression and discriminatory power of miR-30d for NSCLC in each of the included GSE datasets are illustrated in Fig. 2 and $\mathrm{S} 1$ (For all supplemental material see www.karger. com/ 10.1159/000494875/).

As shown in the forest plot of pooled SMD and 95\% CIs, samples from patients with NSCLC exhibited lower miR-30d$5 p$ expression than samples from non-cancer patients (Fig. 3A). The heterogeneity test showed significant heterogeneity among microarrays. Therefore, the random-effects model was applied to assess the pooled SMDs and 95\% CIs. In the subgroup analysis of sample types, lower miR-30d-5p expression was more obvious in group of tissues (Fig. 3B). Nevertheless, heterogeneity between GSE datasets from tissue groups remained significant. The sensitivity analysis also failed to identify the origin of heterogeneity, as no study caused a significant deviation from the overall pooled results (data not shown). Regarding publication bias, Egger's test indicated a lack of publication bias among all included studies $(\mathrm{P}=0.373$ ) (data not shown). Furthermore, the favorable discriminatory power of miR-30d-5p expression from all GSE datasets was reflected in the SROC curves shown in Fig. 4A and the forests plots for overall SEN, SPE, PLR and NLR (Fig. 5). However, the distinguishing ability of circulating miR-30d-5p in GSE datasets sampling miR-30d-5p from plasma reported was weaker than that of miR-30d-5p
Table 3. Diagnostic data of all included GSE datasets. Note: TP: true positivity; FP: false positivity; FN: false negativity; TN: true negativity

\begin{tabular}{lcccc}
\hline ID & TP & FP & FN & TN \\
\hline GSE17681 & 12 & 4 & 5 & 15 \\
GSE27486 & 18 & 12 & 5 & 10 \\
GSE31568 & 22 & 48 & 34 & 33 \\
GSE40738 & 48 & 22 & 33 & 34 \\
GSE46729 & 4 & 1 & 20 & 23 \\
GSE61741 & 41 & 32 & 31 & 62 \\
GSE68951 & 10 & 1 & 16 & 11 \\
GSE16512 & 9 & 0 & 5 & 3 \\
GSE15008 & 164 & 55 & 124 & 132 \\
GSE16025 & 8 & 6 & 2 & 55 \\
GSE19945 & 8 & 4 & 0 & 16 \\
GSE25508 & 22 & 9 & 2 & 15 \\
GSE47525 & 14 & 1 & 0 & 17 \\
GSE48414 & 17 & 27 & 3 & 127 \\
GSE51853 & 5 & 23 & 0 & 101 \\
GSE63805 & 26 & 5 & 4 & 27 \\
GSE72526 & 16 & 2 & 2 & 65 \\
GSE74190 & 42 & 18 & 2 & 48 \\
GSE77380 & 12 & 1 & 0 & 2 \\
GSE2564 & 4 & 4 & 0 & 10 \\
GSE29248 & 6 & 3 & 0 & 3 \\
GSE56036 & 27 & 1 & 2 & 28 \\
GSE93300 & 0 & 2 & 4 & 7 \\
\hline
\end{tabular}




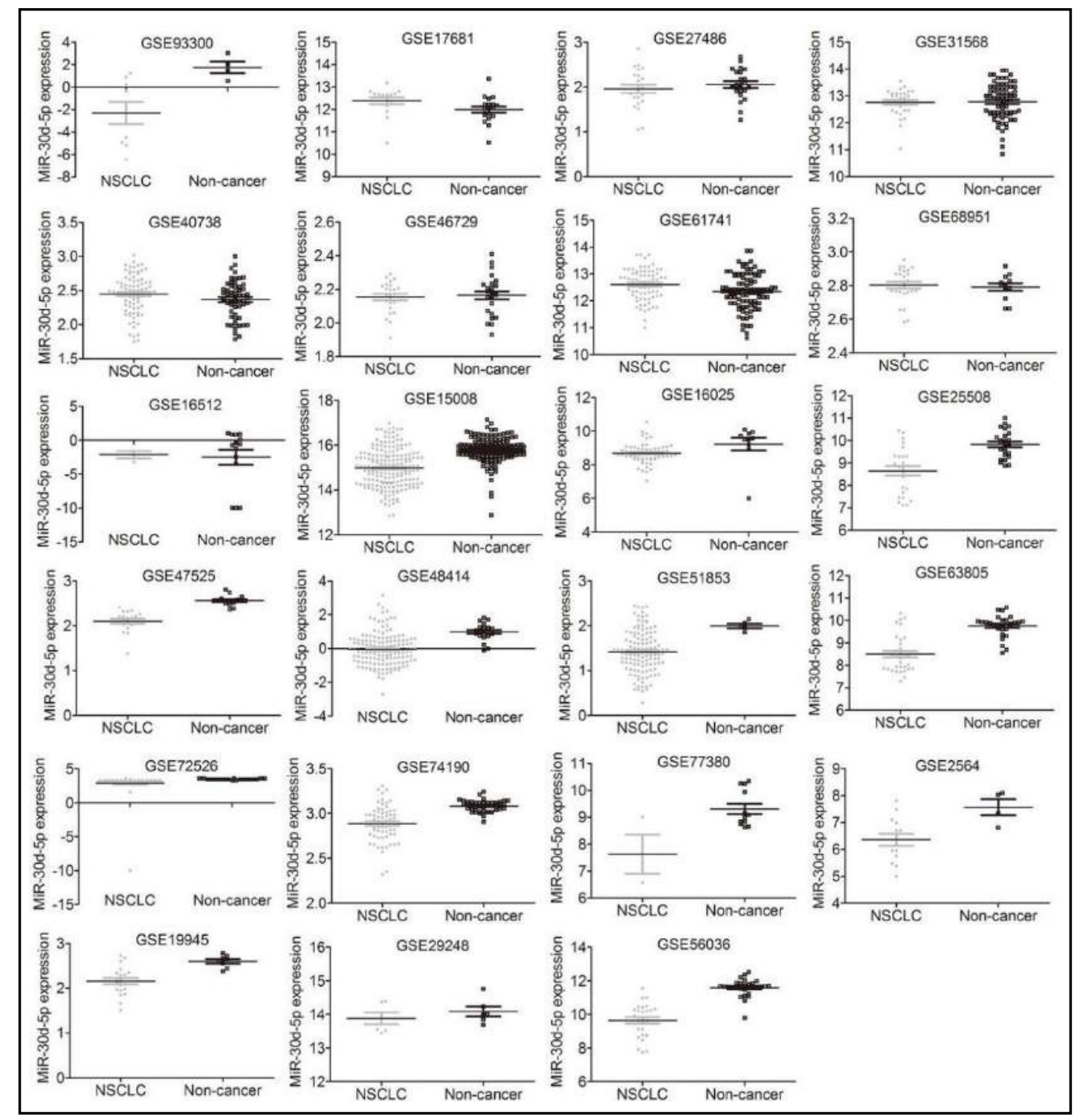

Fig. 2. MiR-30d-5p expression in each of the included GSE datasets. The scatter plots display the differential expression levels of miR-30d-5p in NSCLC tissues and non-cancer tissues for each of the included GSE datasets.

in all GSE datasets (Fig. 4B).

Validation of miR-30d-5p expression in NSCLC using miRNA-sequencing data from TCGA

Scatter plot for miRNA-sequencing data showed that significantly lower miR-30d-5p expression was detected in NSCLC tissues than in normal tissues $(\mathrm{P}<0.001)$ (Fig. 1B).

The integrated meta-analysis incorporating GEO microarray chips, TCGA data, in-house RT-qPCR and literature stuides

After a thorough literature survey of miR-30d-5p expression in NSCLC and non-cancer tissues, we included only two literature studies that provided the expression data of miR$30 d-5 p$ in NSCLC $(9.273 \pm 1.007$ for 26 NSCLC tissues in the study of Nymark P et al.; $0.47 \pm 0.4$ for 50 NSCLC tissues in the study of Wu Y et al.) and non-cancer tissues $(10.775 \pm 0.933$ for 26 non-cancer tissues in the study of Nymark P et al.; $0.99 \pm 0.05$ for 50 non-cancer tissues in the study of Wu Y et al.) [37, 38]. The integrated meta-analysis incorporating all data from 
Fig. 3. The forest plot and subgroup analysis for GEO meta-analysis of miR-30d-5p expression in NSCLC. A: MiR-30d$5 \mathrm{p}$ presented lower expression in NSCLC tissues compared with non-cancer tissues $(\mathrm{SMD}=-0.77, \quad 95 \% \mathrm{CI}$ $=-1.13-0.40, \quad \mathrm{I}^{2}$ $=89.7 \%, \quad \mathrm{P} \quad<0.001$ ), with considerable heterogeneity. B: Subgroup analysis was conducted to assess the influence of sample type on the heterogeneity of the studies. The pooled SMD for the plasma and tissue subgroups were 0.11 (-0.13-0.36) and -1.27 (-1.63--0.91), respectively. Significant heterogeneity still existed in subgroup of tissue $\left(\mathrm{I}^{2}=79.1 \%\right)$.

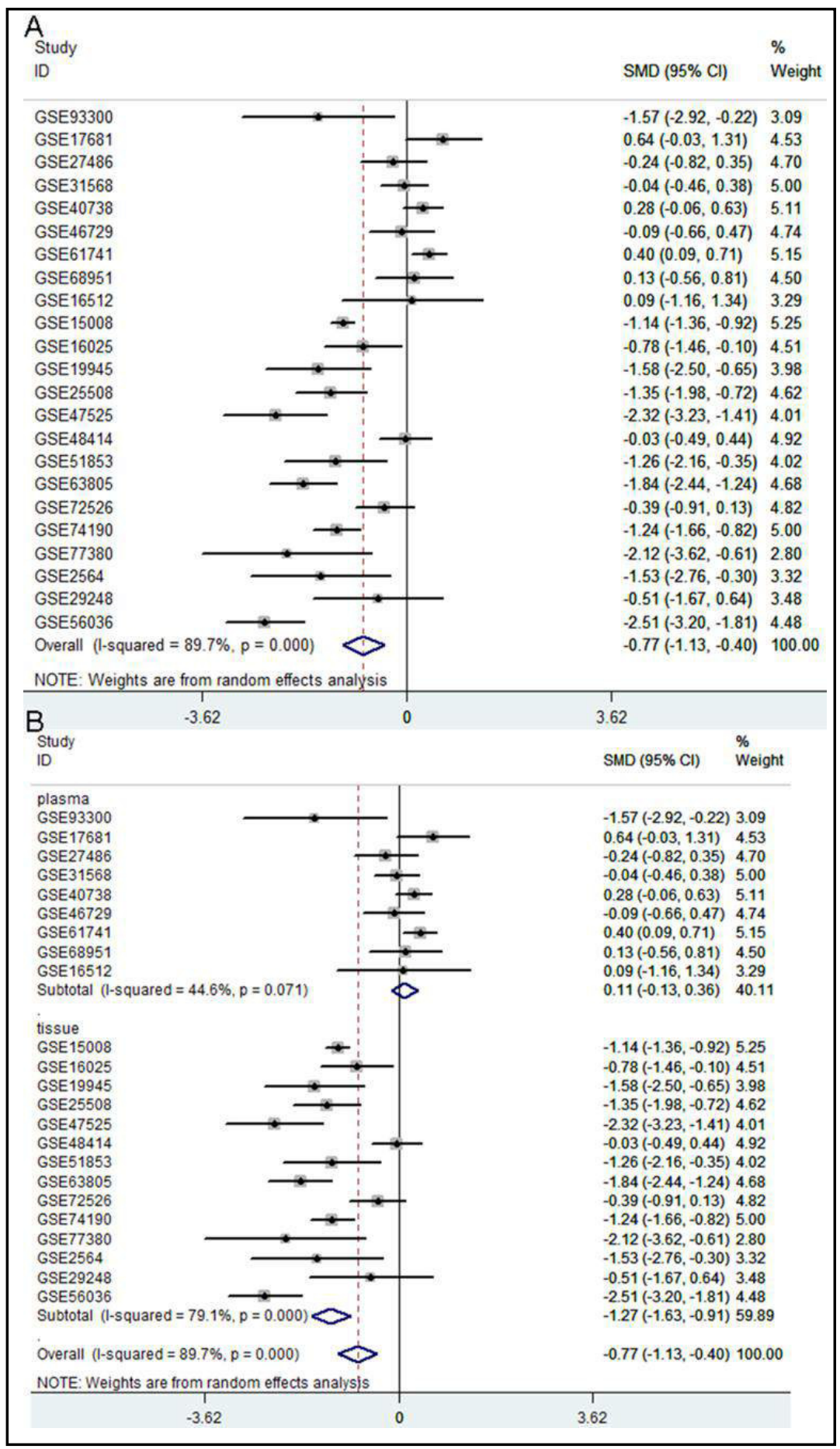

RT-qPCR, GSE datasets, TCGA miR-seq data and literature studies reported consistent results with the meta-analysis of GSE datasets. The down-regulation of miR-30d-5p expression in NSCLC tissues was confirmed by the forest plot shown in Fig. 6A. In particular, the decrease in miR-30d-5p expression was more distinct in NSCLC samples derived from tissues (Fig. 6B). Results from the sensitivity analysis were similar to the corresponding part of the metaanalysis of GSE datasets (data not shown). High AUC value (Fig. 7) as well as pooled SEN, SPE, PLR and NLR values indicated the fine discriminatory power of miR-30d-5p in distinguishing NSCLC tissues from non-cancer tissues (Fig. 8). 
Fig. 4. SROC curves for GEO meta-analysis. A: SROC curves for all the included GSE datasets. The AUC value of the SROC curves was 0.8500, indicating favorable discriminatory ability of miR-30d-5p in NSCLC. B: SROC curves for GSE datasets sampling miR-30d$5 \mathrm{p}$ from plasma. The AUC value of the SROC curves was 0.6312, indicating weak diagnostic value of circulating miR-30d$5 p$ in NSCLC.

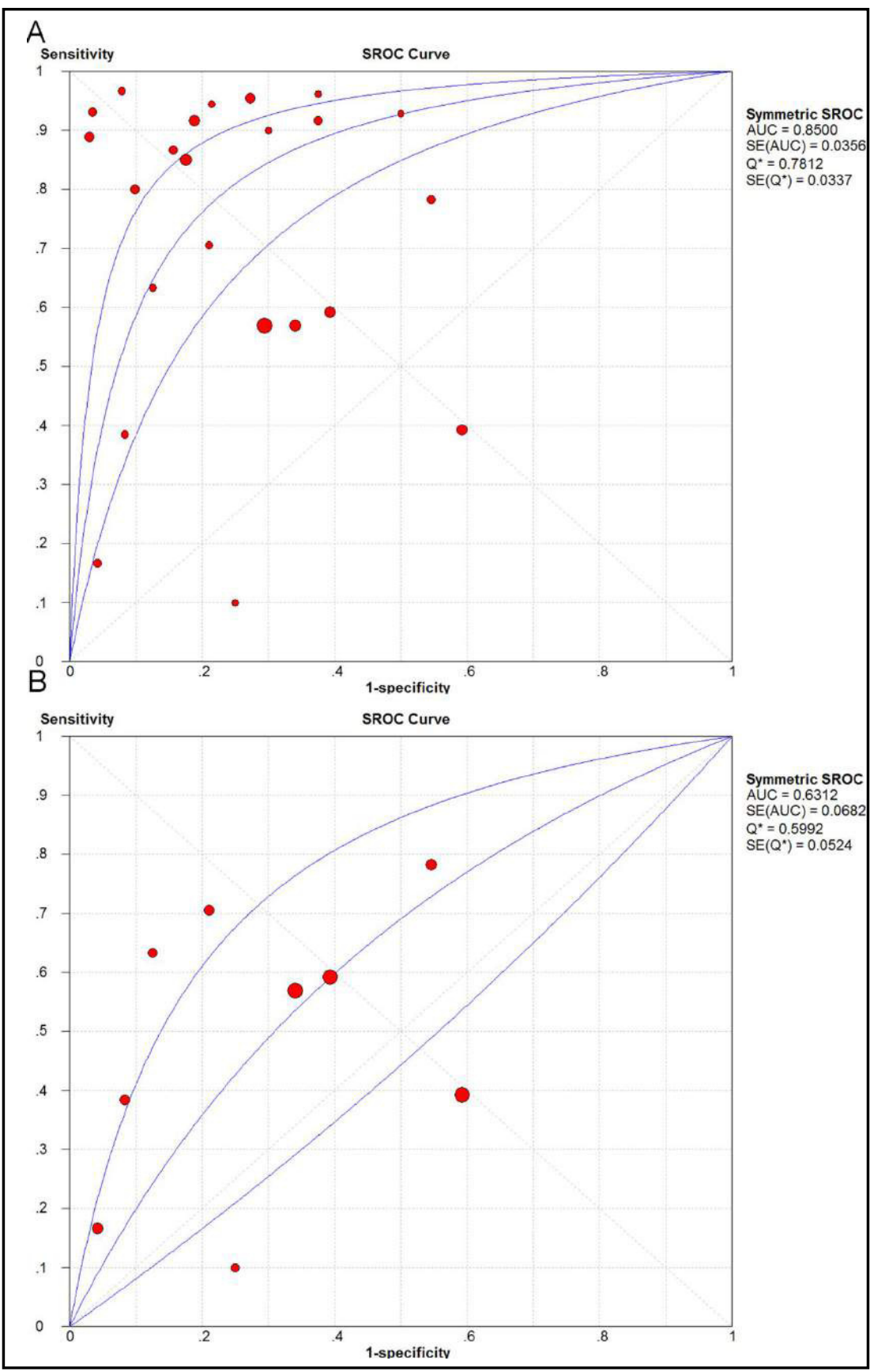

The prognostic significance of miR-30d-5p expression for NSCLC

The Kaplan-Meier survival analysis for RT-qPCR data revealed a trend that the prognosis of patients with NSCLC who presented with higher miR-30d-5p expression was better than patients with lower miR-30d-5p expression, although the result only displayed weak statistical significance (Fig. 9A).

With respect to prognostic meta-analysis, a total of 1113 studies were included in the initial search for prognostic meta-analysis. After scanning the titles and abstracts, we excluded 1090 studies. Eventually, four suitable studies were included in the meta-analysis [39-42]. Basic information from the included studies is listed in Table 4. Since no direct HRs and $95 \%$ CIs were provided in the study by Czubak K et al. [41], we extracted the HRs and 


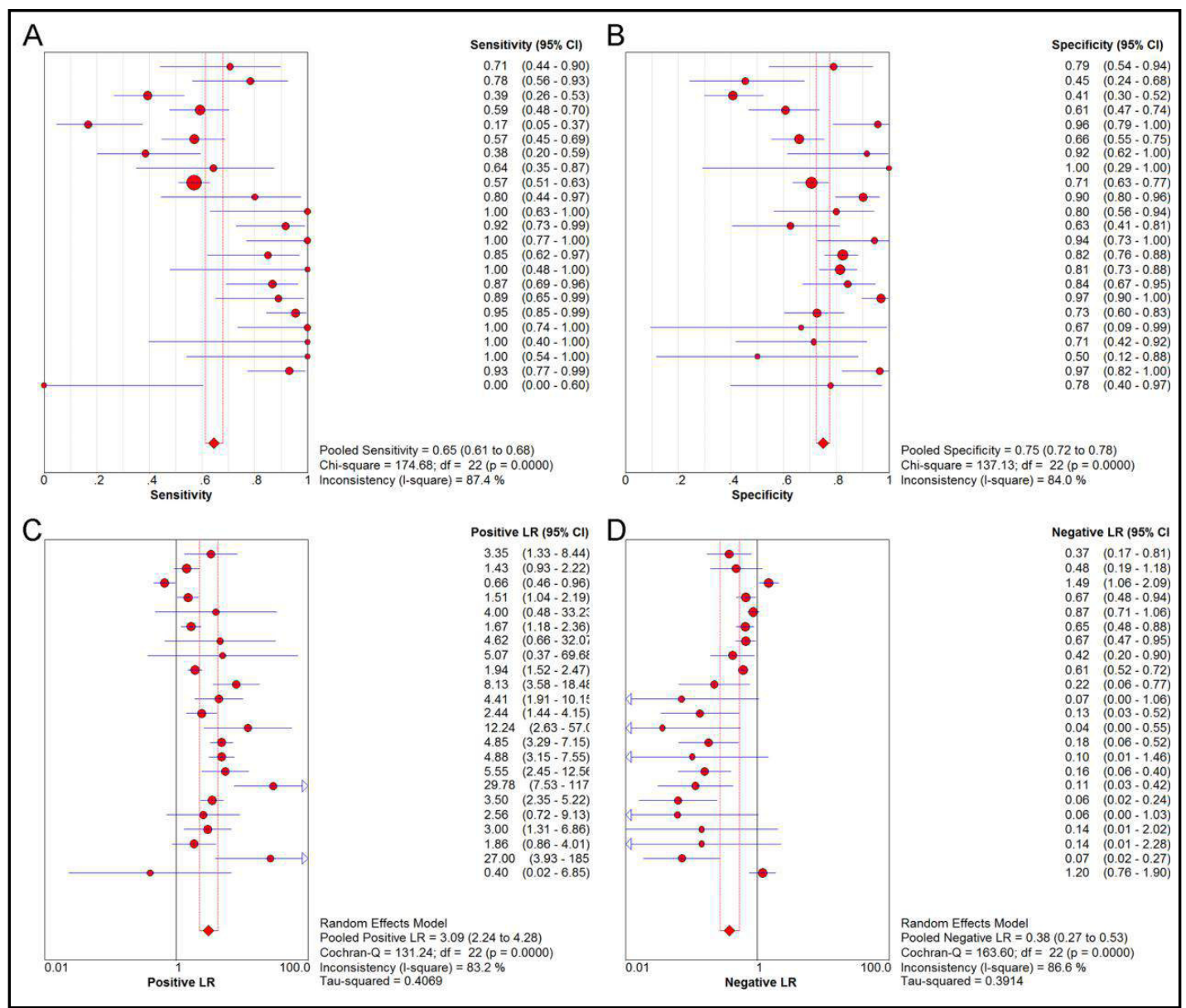

Fig. 5. Forest plot of the discriminatory ability of miR-30d-5p in NSCLC from all included GSE datasets. A: SEN: 0.65 (95\%CI: 0.61-0.68). B: SPE: 0.75 (95\%CI: 0.72-0.78). C: PLR: 3.09 (95\%CI: 2.24-4.28). D: NLR: 0.38 (95\%CI: 0.27-0.53).

95\% CIs from the Kaplan-Meier survival curves. The forest plot shown in Fig. 9B depicted miR-30d-5p expression as a risk factor for the prognosis of NSCLC patients. Nevertheless, the result was statistically insignificant because the 95\%CI for HR contained zero. The subsequent subgroup analysis revealed that plasma miR-30d-5p levels were more likely to serve as a risk factor for the survival of patients with NSCLC than miR-30d-5p levels in tissues (Fig. 9C). Sensitivity analysis did not reveal a significant impact of any study on the results obtained from whole study cohort, and publication bias was not detected by Begg's and Egger's tests (data not shown).

\section{Results from in vitro experiments}

As illustrated in Fig. 10, cell proliferation evaluated by MTT assays decreased sharply at $96 \mathrm{~h}$ in all five cell lines transfected with miR-30d-5p mimic. The negative influence of miR30d-5p mimic on cell proliferation was observed to be most significant in $\mathrm{H} 460$ cell lines, in which obviously diminished cell proliferation started at $48 \mathrm{~h}$ and continued until $96 \mathrm{~h}$ (Fig. 10C). For the influence of miR-30d-5p on cell viability, fluorometric resorufin viability assay reflected almost the same effect of miR-30d-5p on cell growth as MTT assays (Fig. 11). 
Fig. 6. The forest plot and subgroup analysis for the integrated meta-analysis of miR30d-5p expression in NSCLC. A: MiR-30d$5 \mathrm{p}$ showed lower expression in NSCLC tissues compared with that in non-cancer tissues (SMD $=-0.85$, $95 \%$ CI $=-1.17-0.54$, $\left.\mathrm{I}^{2}=91.0 \%, \mathrm{P}<0.001\right)$, with considerable study heterogeneity. B: Subgroup analysis was conducted to assess the influence of sample type on the heterogeneity of the studies. The pooled SMD for the plasma and tissue subgroups were $0.11 \quad(-0.13-0.36)$ and $-1.27 \quad(-1.56-0.98)$, respectively. Significant heterogeneity still existed in the subgroup of tissue $\left(I^{2}=83.4 \%\right)$.

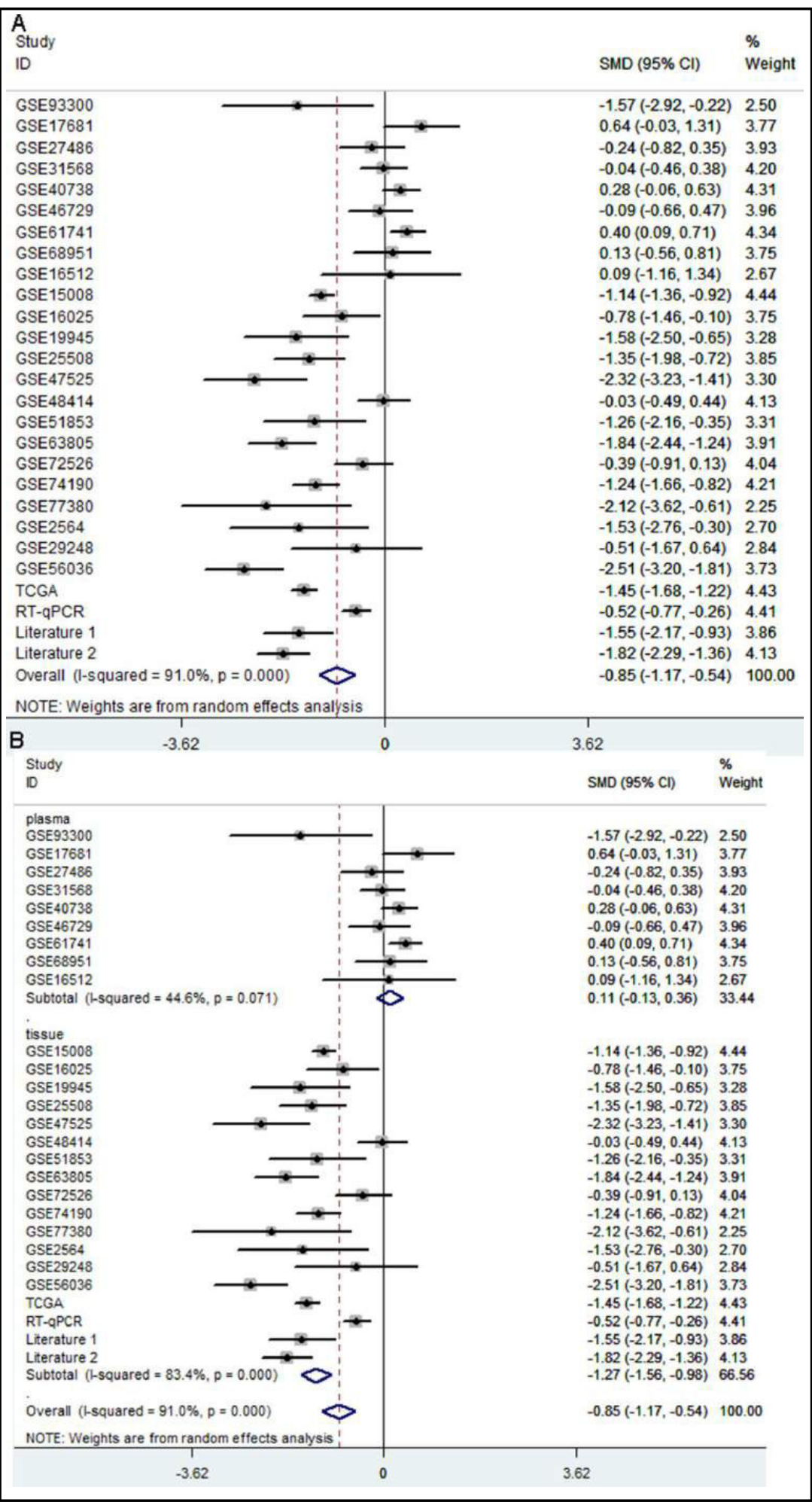


Fig. 7. SROC curves for the integrated metaanalysis of miR-30d-5p expression in NSCLC. The AUC value of the SROC curves was 0.8450, indicating favorable distinguishing capacity of miR-30d-5p in NSCLC.
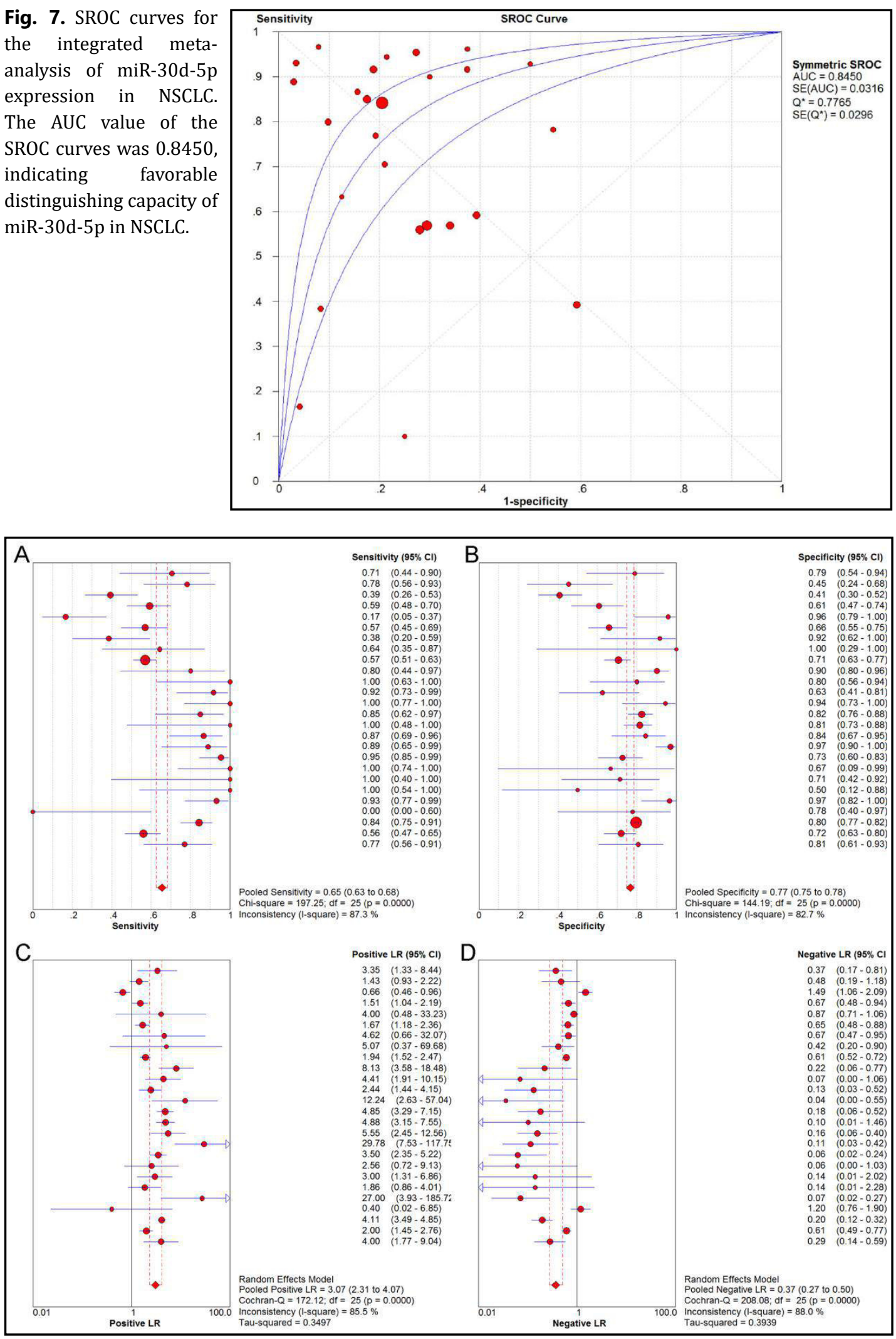

Fig. 8. Forest plots of discriminatory ability of miR-30d-5p in NSCLC for the integrated meta-analysis. A: overall SEN: 0.65 (95\%CI: 0.63-0.68). B: overall SPE: 0.77 (95\%CI: 0.75-0.78). C: overall PLR: 3.07 (95\%CI: 2.31-4.07). D: overall NLR: 0.37 (95\%CI: 0.27-0.50). 


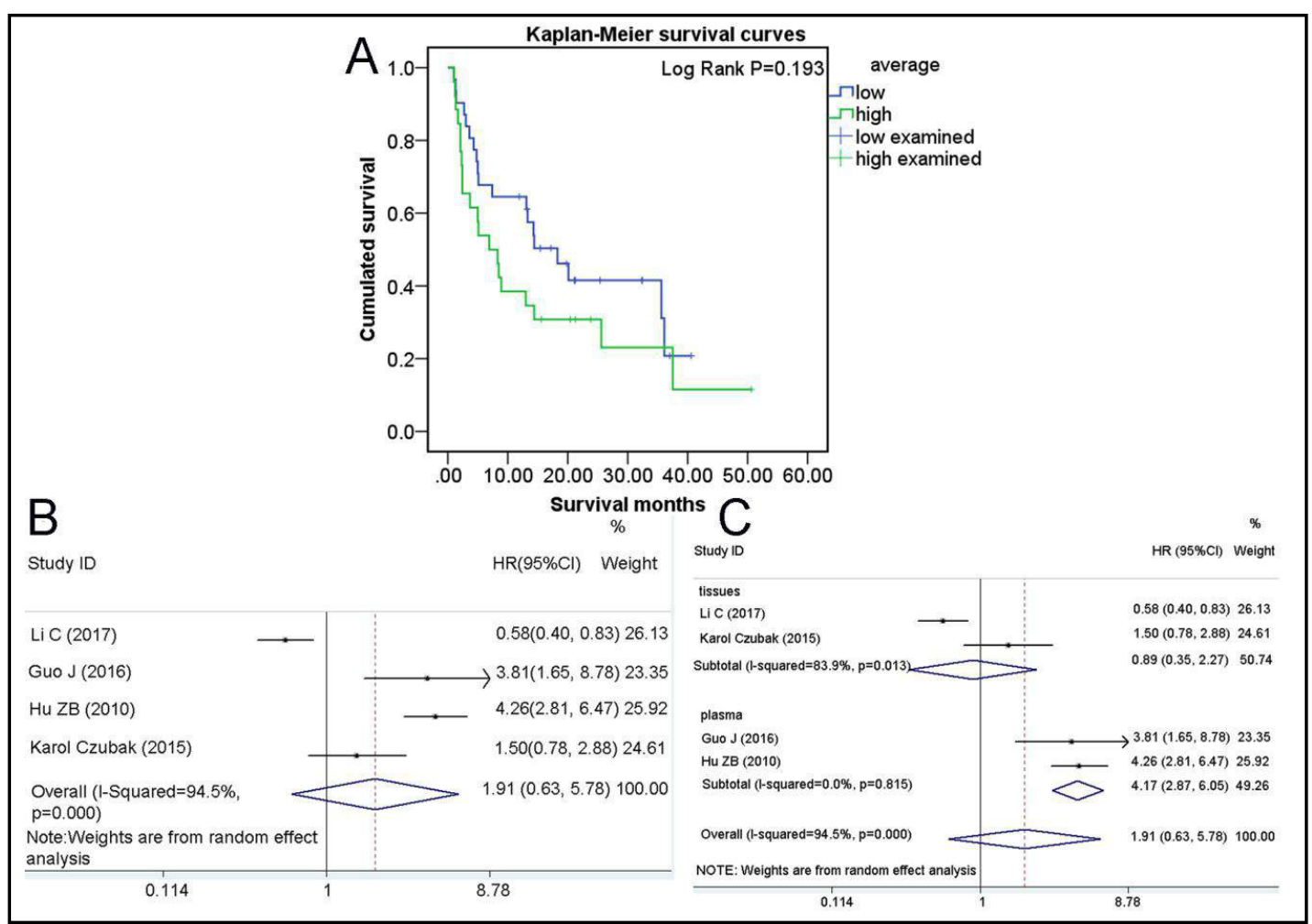

Fig. 9. Kaplan-meier survival analysis for RT-qPCR data and the prognostic meta-analysis. (A) Despite P value from Log-rank test was insignificant $(\mathrm{P}=0.193)$, it can be seen from the Kaplan-Meier Survival curves that the prognosis of NSCLC patients with higher miR-30d-5p expression was better than those with lower miR-30d-5p expression. (B) Forest plot of HR and 95\%CI. (C) Subgroup analysis based on sample type.

Table 4. Basic information of the included literature studies. Note: OS: overall survival; PFS: progressionfree survival; HR: hazord ratio; LL: lower limit; UL" upper limit. Patients in the study of Czubak K et al. were divided according to the copy number variation of miR-30d-5p; therefore, no cut-off value was provided in this study

\begin{tabular}{|c|c|c|c|c|c|c|c|c|c|c|c|}
\hline $\begin{array}{l}\text { First } \\
\text { author }\end{array}$ & $\begin{array}{c}\text { Publication } \\
\text { year }\end{array}$ & Country & $\begin{array}{c}\text { Sample } \\
\text { size }\end{array}$ & Cut-off & Method & $\begin{array}{c}\text { Survival } \\
\text { type }\end{array}$ & HR & LL & UL & $\begin{array}{c}\text { Sample } \\
\text { type }\end{array}$ & $\begin{array}{c}\text { Reference } \\
\text { number }\end{array}$ \\
\hline Li C & 2017 & China & 423 & & a & OS & 0.5 & 0.4 & & & \\
\hline Guo J & 2016 & China & 34 & & lysis & PFS & 3.8 & & & & [41] \\
\hline $\mathrm{Iu}$ ZB & 010 & & 303 & & & & 4.26 & & 6.47 & & [42] \\
\hline Karol Czubak & 2015 & Poland & 120 & & Kaplan-Meier survival curves & OS & 1.5 & 0.78 & 2.88 & tissues & [40] \\
\hline
\end{tabular}

\section{Bioinformatics analysis of miR-30d-5p target genes}

Two thousand four hundred twelve target genes appeared in the prediction lists from at least six online prediction programs and 14399 up-regulated genes with a FDR value of less than 0.05 were selected from the TCGA database. After consolidating the overlapping results from the two databases, 507 candidate target genes were screened in subsequent bioinformatics analysis.

Among the 121 recorded significant GO terms $(\mathrm{P}<0.05)$, the target genes were mainly involved in the BP neuron migration, positive regulation of transcription from RNA polymerase II promoter and axon guidance (Table 5). The target genes were significantly clustered in the following CC: cell junction, cell surface and plasma membrane (Table 5). The top three significant terms in the MF category were transcriptional activator activity, RNA polymerase II core promoter, and sequence-specific DNA binding and transcription factor activity (Table 5). GO enrichment plots for BPs, CCs and MFs for the target genes are shown in Fig. S2A-S2C. 
The functional analysis of the involvement of target genes in pathways was analyzed using the KEGG. A total of nine pathways including mucin type 0-glycan biosynthesis, cell cycle and cysteine and methionine metabolism pathway, were significantly related to target genes $(\mathrm{P}<0.05)$, and the top three KEGG pathways were displayed in Table 5. Specifically, PPI networks were created to illustrate the interactions of target genes engaged in the top three significant KEGG pathways (Fig. S2D). By counting the degree of connectivity of the target genes in PPI networks, we identified 12 genes, B3GNT6, ST6GALNAC1, E2F3, CCNA1, CCNE2, TFDP1, SKP2, CDK6, LDHA, GOT2, DNMT3B and DNMT3A, as the hub genes because they possessed a relatively greater number connections in the corresponding PPI networks.

According to results of the DO analysis (Fig. S2E), the significant disease enriched by target genes of miR-30d-5p was developmental disorder of mental health.

\section{Validation of hub genes}

Pearson's correlation analysis conducted in GraphPad Prism software v 5 implied that seven of the 12 hub genes (E2F3, CCNE2, SKP2, CDK6, LDHA, GOT2 and DNMT3B) were negatively correlated with miR-30d-5p expression (all $\mathrm{P}<0.05$ ) (Fig. 12). HPA database confirmed the overexpression of the following hub genes in NSCLC

Fig. 10. The influence of miR-30d$5 \mathrm{p}$ on cell proliferation of the tested cell lines. A: A549 cell lines. B: H292 cell lines. C: H460 cell lines. D: H1299 cell lines. E: PC9 cell lines. Points and bars represent the average of three repeated experiments and the standard deviation, respectively. ${ }^{* *} \mathrm{P}$ $<0.01$ and ${ }^{* * *} \mathrm{P}<0.001$. Comparisons were conducted between the miR$30 \mathrm{~d}-5 \mathrm{p}$ mimic group or the miR$30 \mathrm{~d}-5 \mathrm{p}$ inhibitor group and the corresponding negative or blank groups at the same time point.
Table 5. GO and KEGG pathway analysis of the target genes of miR30d-5p. Note: BP: biological process; CC: cellular component; MF: molecular function. Only top three GO terms for BP, CC and MF as well as KEGG pathways were displayed in the table

\begin{tabular}{|c|c|c|c|c|c|}
\hline Category & ID & Term & Count & $\%$ & $P$ value \\
\hline GOTERM_BP_DIRECT & GO:0001764 & $\begin{array}{c}\text { neuron migration } \\
\text { positive regulation of }\end{array}$ & 14 & 2.777777778 & $4.94 \mathrm{E}-06$ \\
\hline GOTERM_BP_DIRECT & GO:0045944 & $\begin{array}{l}\text { transcription from RNA } \\
\text { polymerase II promoter }\end{array}$ & 50 & 9.920634921 & $2.31 \mathrm{E}-05$ \\
\hline GOTERM_BP_DIRECT & GO:0007411 & axon guidance & 16 & 3.174603175 & $2.70 \mathrm{E}-05$ \\
\hline GOTERM_CC_DIRECT & GO:0030054 & cell junction & 30 & 5.952380952 & $1.19 \mathrm{E}-05$ \\
\hline GOTERM_CC_DIRECT & GO:0009986 & cell surface & 31 & 6.150793651 & $9.77 \mathrm{E}-05$ \\
\hline GOTERM_CC_DIRECT & GO:0005886 & $\begin{array}{c}\text { plasma membrane } \\
\text { transcriptional activator }\end{array}$ & 142 & 28.17460317 & $1.95 \mathrm{E}-04$ \\
\hline GOTERM_MF_DIRECT & GO:0001077 & $\begin{array}{l}\text { activity, RNA polymerase II } \\
\text { core promoter }\end{array}$ & 22 & 4.365079365 & $1.16 \mathrm{E}-06$ \\
\hline GOTERM_MF_DIRECT & GO:0043565 & $\begin{array}{c}\text { sequence-specific DNA } \\
\text { binding }\end{array}$ & 34 & 6.746031746 & $2.64 \mathrm{E}-06$ \\
\hline GOTERM_MF_DIRECT & GO:0003700 & $\begin{array}{l}\text { transcription factor activity, } \\
\text { sequence-specific DNA } \\
\text { binding }\end{array}$ & 46 & 9.126984127 & $1.19 \mathrm{E}-04$ \\
\hline KEGG_PATHWAY & hsa00512 & $\begin{array}{l}\text { Mucin type O-Glycan } \\
\text { biosynthesis }\end{array}$ & 6 & 1.19047619 & 0.001057396 \\
\hline KEGG_PATHWAY & hsa 04110 & Cell cycle & 9 & 1.785714286 & 0.014437641 \\
\hline KEGG_PATHWAY & hsa 00270 & $\begin{array}{l}\text { Cysteine and methionine } \\
\text { metabolism }\end{array}$ & 5 & 0.992063492 & 0.015878523 \\
\hline
\end{tabular}

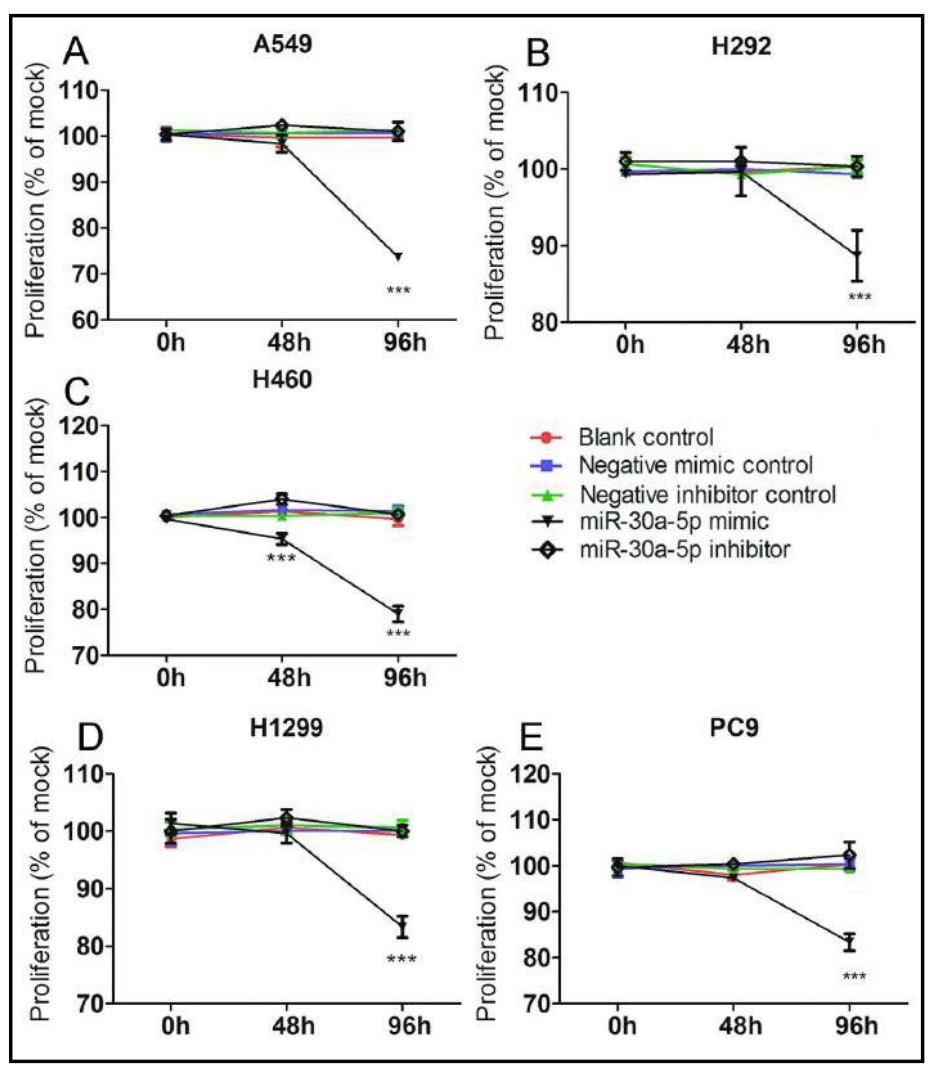


Fig. 11. The influence of miR-30d-5p on cell viability of the tested cell lines. A: A549 cell lines. B: H292 cell lines. C: H460 cell lines. D: H1299 cell lines. E: PC9 cell lines. Columns and bars represent the average of three repeated experiments and the standard deviation, respectively. ** $\mathrm{P}<0.01$ and ***P $<0.001$. Comparisons were conducted between the miR-30d-5p mimic group or the miR-30d-5p inhibitor group and the corresponding negative or blank groups at the same time point.
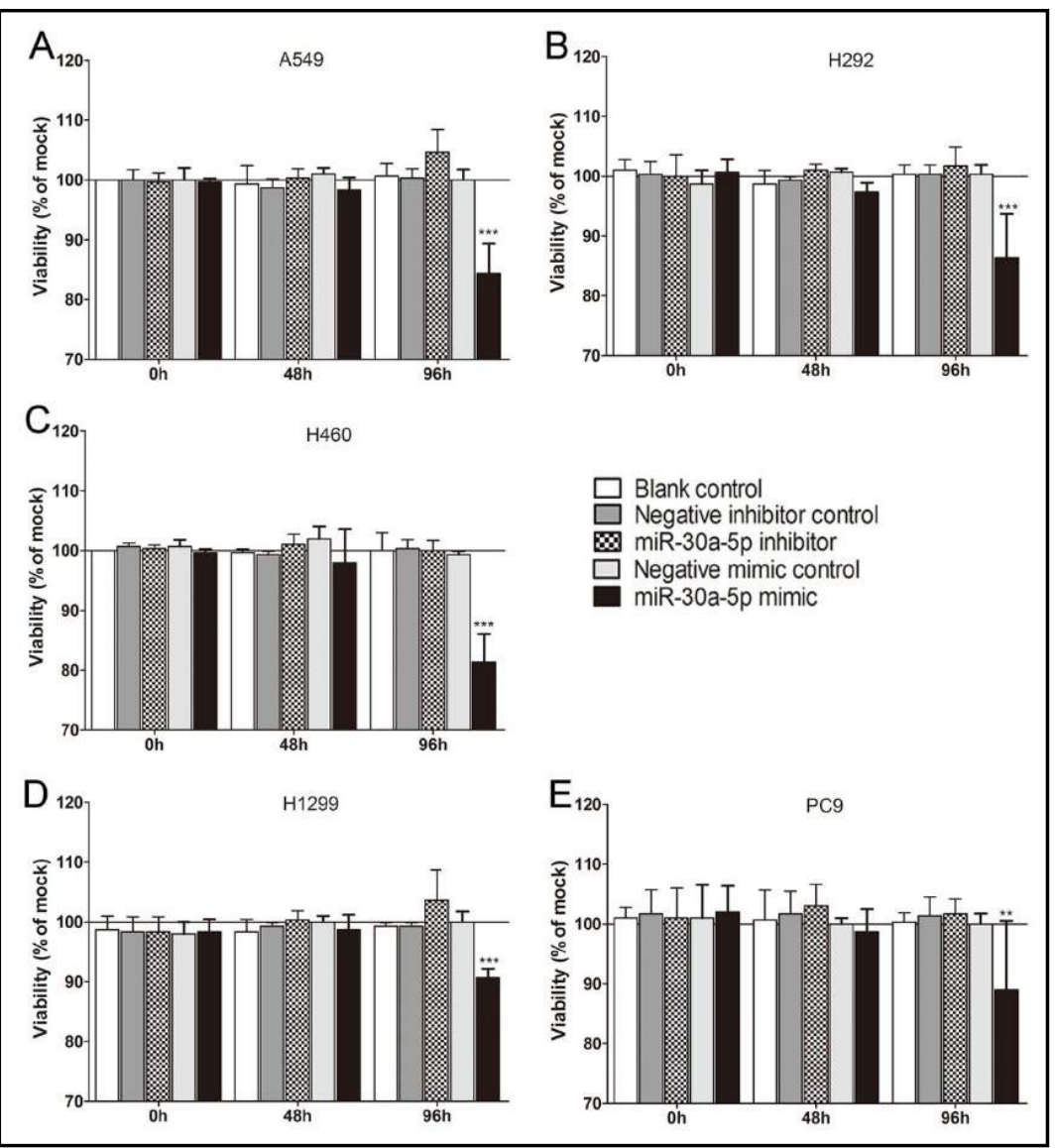

tissues: CCNE2 (antibody CAB007825), DNMT3B (antibody HPA001595), SKP2 (antibody CAB013491), GOT2 (antibody HPA018139), LDHA

(antibody CAB015336), ST6GALNAC1 (antibody HPA014975), and TFDP1 (antibody CAB033605) (Fig. 13). The moderate or high staining intensity of these five proteins in NSCLC tissues contrasted sharply with the low intensity or lack of staining in normal lung tissues.

Based on the above mentioned validation results, a total of five genes including CCNE2, DNMT3B, SKP2, GOT2 and LDHA were simultaneously validated by Pearson's correlation test and HPA database to present higher expression in NSCLC tissues. We noted that CCNE2 appeared in the prediction lists with the highest frequency (nine databases). Therefore, we conducted dual luciferase reporter assay to further verify whether CCNE2 was directly targeted by miR-30d-5p.

We identified a binding site for miR-30d-5p in the 3'-UTR of CCNE2 mRNA with the aid of online prediction programs: miRANDA and Targetscan (Fig. 14A). In luciferase reporter assay, we found that the luciferase activity decreased substantially in HEK-293T cells cotransfected with psiCHECK-2/CCNE2 3'-UTR and miR-30d-5p mimics, compared with controls (Fig. 14B). This outcome revealed that CCNE2 was a direct target of miR-30d-5p. 


\section{Cellular Physiology

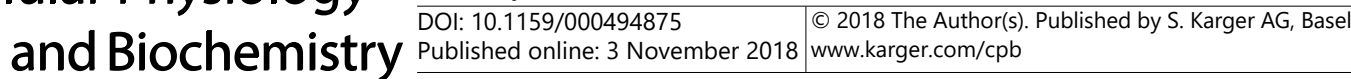

Gao et al.: miR-30d-5p: Expression Signature and Tumor Suppressive Role in NSCLC

Fig. 12. Pearson correlation analysis of miR-30d$5 \mathrm{p}$ expression and the expression of hub genes. The correlation diagrams depict the correlations between miR-30d-5p expression and the expression of hub genes from key KEGG pathway. Expression of E2F3, CCNE2, SKP2, CDK6, LDHA, GOT2 and DNMT3B showed significant correlation with miR-30d-5p expression in NSCLC (all $\mathrm{P}<0.05)$.

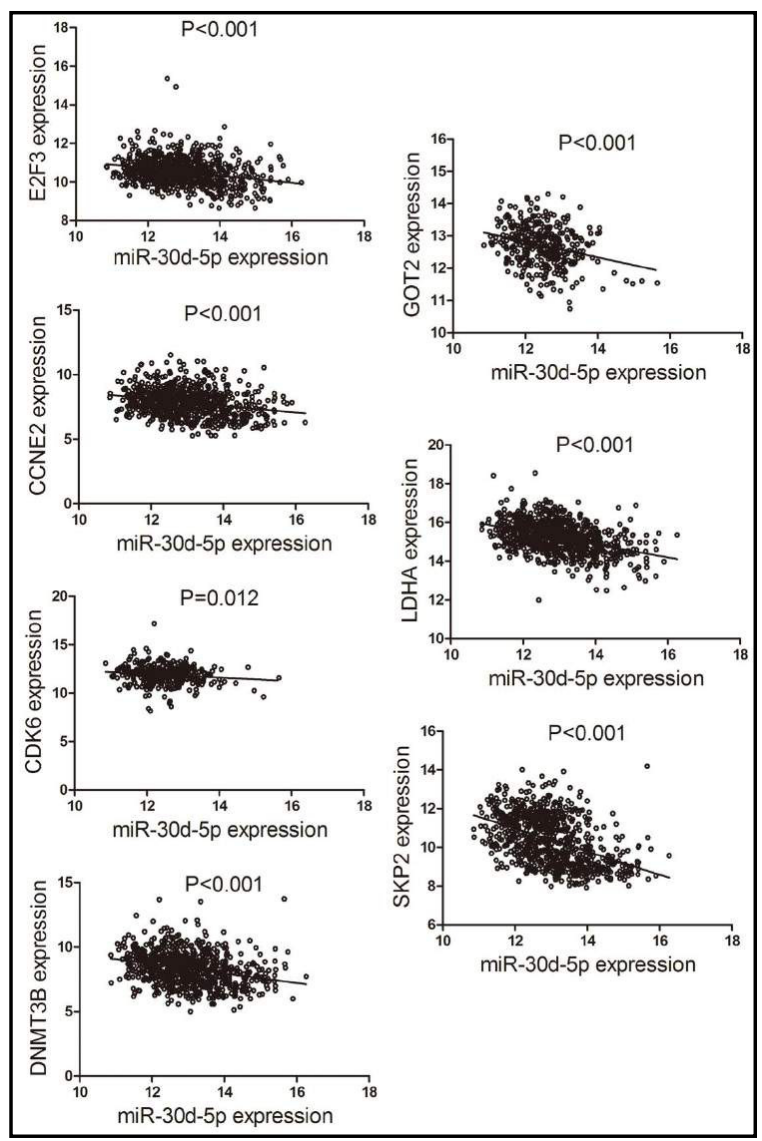

Fig. 13. Immunohistochemistry of hub genes from key KEGG pathway in NSCLC tissues and normal tissues. A: CCNE2 expression in NSCLC tissues (antibody CAB007825). B: CCNE2 expression in normal tissues (antibody CAB007825). C: DNMT3B expression in NSCLC tissues (antibody HPA001595). D: DNMT3B expression in normal tissues (antibody HPA001595). E: SKP2 expression in NSCLC tissues (antibody CAB013491). F: SKP2 expression in normal tissues (antibody CAB013491). G: GOT2 expression in NSCLC tissues (antibody HPA018139). H: GOT2 expression in normal tissues (antibody HPA018139). I: LDHA expression in NSCLC tissues (antibody CAB015336). J: LDHA expression in normal tissues (antibody CAB015336). K: ST6GALNAC1 expression in NSCLC tissues (antibody HPA014975).

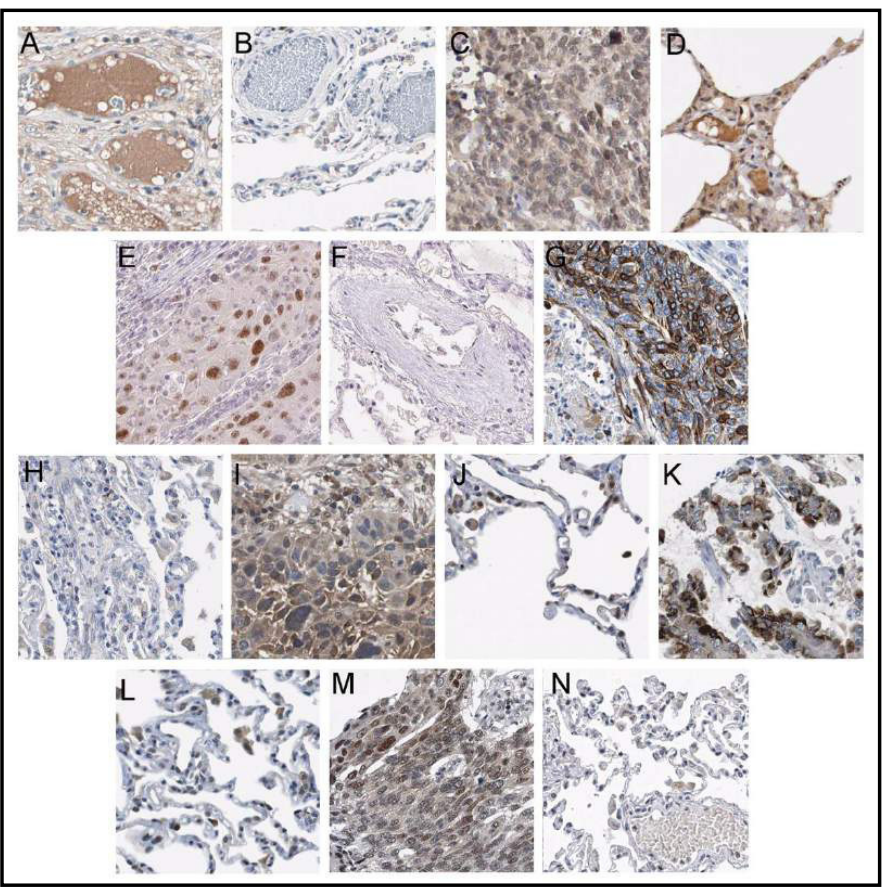
L: ST6GALNAC1 expression in normal tissues (antibody HPA014975). M: TFDP1 expression in NSCLC tissues (antibody CAB033605). N: TFDP1 expression in normal tissues (antibody CAB033605). From the immunohistochemistry results of the HPA, all the above genes showed medium or high immunostaining in NSCLC tissues. Conversely, low or no immunoreactivity of these genes was detected in normal tissues. 


\section{Discussion}

Current studies have reported the down-regulation of miR-30d$5 \mathrm{p}$ expression in NSCLC, and miR$30 d-5 p$ exerts inhibitory effects on the proliferation, motility and invasion of NSCLC cells $[25,35$, 38]. Nevertheless, the underlying molecular mechanism by which miR$30 \mathrm{~d}-5 \mathrm{p}$ regulates the tumorigenesis of NSCLC remains elusive.

In the present study, miR$30 d-5 p$ down-regulation in NSCLC was supported by rich samples of 1995 NSCLC patients and 994 non-cancer patients from RT-qPCR, GEO and TCGA databases, which guaranteed the reliability of our results. Additionally, the clinicpathological significance of miR$30 d-5 p$ in NSCLC calculated from RT-qPCR data results were consistent with the findings from the studies by Wu Y et al. and Chen D et al., showing that miR-30d-5p exerted inhibitory influences on tumor progression of NSCLC $[25,38]$. We also appraised the prognosis-predicting and discriminatory ability of miR-30d-5p in NSCLC to achieve a comprehensive assessment of the clinico-pathological value of miR-30d-5p in NSCLC. Since assessment results from survival analysis for RT-qPCR data and the prognostic meta-analysis reported conflicting influence of miR-30d-5p on the prognosis of NSCLC patients, we could not conclude the prognostic significance of miR-30d$5 p$ for NSCLC in the present study. With regard to the discriminatory capacity of miR-30d-5p, the favorable distinguishing ability revealed by both the SROC curves for GEO meta-analysis and the integrated meta-analysis hinted at the potential use of miR-30d-5p for screening of NSCLC. Considering the non-invasive nature of the circulating miRNA-based test, circulating miRNAs might conceivably surpass tissue mRNAs as the most attractive screening tools for NSCLC $[43,44]$. Therefore, a SROC curve was specially created for plasma miR-30d-5p levels. Unfortunately, the diagnostic ability of plasma miR-30d-5p levels for NSCLC in our study was even lower than plasma and tissue miR-30d-5p levels, which might be explained by the phenomenon that miRNAs from blood exosomes were partially taken up by cancer cells in addition to transcribed essential miRNAs, resulting in the relatively lower levels of miRNAs in the blood [45-47]. Further studies are required to confirm whether miR-30d-5p has the potential to be applied as a novel prognostic and diagnostic biomarker for NSCLC.

To gain insights on how miR-30d-5p affects the pathogenesis of NSCLC, we conducted in vitro experiments to explore the influence of miR-30d-5p on cell growth in NSCLC. MTT and fluorometric resorufin viability assay proved that the proliferation and viability of NSCLC cells was restrained notably by miR-30d-5p. The inhibition of tumor cell growth by miR$30 \mathrm{~d}-5 \mathrm{p}$ has also been shown in in vitro experiments with prostate cancer [48]. Therefore, we hypothesized that miR-30d-5p may act as a tumor suppressor in NSCLC through inhibiting tumor growth.

To date, miR-30d-5p has been shown to target several downstream molecules to promote the pathogenesis of human cancers. According to Yan L et al., down-regulated miR$30 \mathrm{~d}-5 \mathrm{p}$ enhances the proliferation and invasion of colorectal carcinoma cells by targeting LRH-1 [49]. In the study by Xie R et al., miR-30d-5p was reported to attenuate the migration and invasion of esophageal squamous cell carcinoma cells by regulating EZH2 expression [50]. In NSCLC, the regulatory relationship between miR-30d-5p and two target molecules, 


\section{Cellular Physiology Cell Physiol Biochem 2018;50:1964-1987

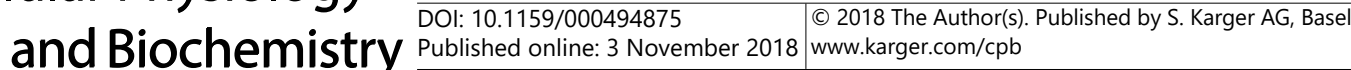

Gao et al.: miR-30d-5p: Expression Signature and Tumor Suppressive Role in NSCLC

CCNE2 and NFIB, have been recorded in the literature $[25,38]$. However, the mere revelation of two target genes of miR-30d-5p is not sufficient to interpret the molecular mechanism by which miR-30d-5p regulates the occurrence and development of NSCLC, because a single miRNA is capable of modulating the expression of hundreds of target genes. Therefore, we focused on the regulatory network of target genes in an attempt to provide new insights into the role of miR-30d-5p in NSCLC.

According to the bioinformatics analysis of the target genes, the enrichment of the target genes in biological processes such as neuron migration, positive regulation of transcription from RNA polymerase II promoter and axon guidance suggested potential molecular functions of miR-30d-5p in NSCLC by regulating the expression of target genes involved in these biological processes. In addition to the GO analysis, we also obtained important clues about the regulatory interactions between the target genes from KEGG pathway analysis. The top three pathways, mucin type 0 -glycan biosynthesis, cell cycle and cysteine and methionine metabolism, all implicated the target genes in the molecular mechanism of NSCLC. Mucintype 0-glycans, important components of mucins, are widely expressed in the mucosa in different parts of the body [51]. Mucin-type 0-glycans play critical roles in the promoting the barrier function of mucus and mediating the mutualism of host and the microbial community [52-54], which has been extensively studied in the intestinal epithelium. We postulated that the dysfunction of mucin-type 0-glycans in lung tissues might damage the barrier function of the respiratory tract mucosa and cause an imbalance in local microbial community, which would subsequently initiate the oncogenesis of NSCLC. Regarding the cell cycle pathway, an uncontrolled cell cycle is acknowledged as one of the hallmarks of various cancers, including NSCLC [55]. We speculate that the target genes of miR-30d-5p might serve as constituents of cell cycle.

pathways to contribute to the dysregulated growth of NSCLC cells. Another pathway worth mentioning is the cysteine and methionine metabolism pathway. Abnormal cysteine and methionine metabolism has been linked to the formation of human cancers [56-58]. Several studies have elaborated on the methionine-dependency of tumors [56-58]. As shown in the study by Al-Awadi $\mathrm{F}$ et al., a decreased plasma cysteine level is significantly associated with the growth in breast, prostate and pancreatic tumors implanted in nude mouse [59], indicating an effect of cysteine and methionine metabolism on the progression of caners. The participation of the target genes in pathways related to cysteine and methionine metabolism might conceivably predict biological events such as tumor proliferation or invasion in NSCLC.

In further analysis, we emphasized on hub genes, as they contained key information of the complicated interaction networks of the target genes. Although the regulatory relationship between miR-30d-5p and all 12 hub genes, except CCNE2, have not been recorded in the literature, several of these target genes have been reported to correlate with the malignant potential of NSCLC. Silencing of E2F3 by the tumor-suppressor miR449a induces the growth arrest and senescence of NSCLC cells [49]. Transfection of a CCNA1 siRNA into NSCLC cell lines significantly increases the cell cycle arrest and apoptosis of NSCLC cells [60]. SKP2 overexpression in NSCLC tissues and the coordinate suppression of SKP2 by miR-3163 and Megs inhibit the growth of NSCLC tumors [61]. Decreased LDHA expression induced by ectopic miR-499a expression induces apoptosis and DNA damage when cells are exposed to ionizing radiation [62]. The growth of NSCLC cells is significantly retarded upon the inhibition of CDK6 expression via transfection of miR-137 [63]. These findings suggested a possible molecular mechanism underlying the role of miR-30d-5p in the pathogenesis of NSCLC and implied that the tumor-suppressor role of miR-30d-5p in NSCLC might be achieved by targeting these genes. Furthermore, validation from Pearson's correlation analysis or the HPA database to provided indirect evidence for the possible regulatory relationship between miR-30d-5p and these hub genes. Dual-luciferase report assay confirmed CCNE2 to be directly targeted by miR-30d-5p, which strengthened the credibility of our prediction results. Our future studies should be directed at validating the regulatory relationship between miR-30d-5p and other target hub genes, as well as the functional roles of the hub genes in NSCLC through in vivo or in vitro experiments. 


\section{Cellular Physiology Cell Physiol Biochem 2018;50:1964-1987 \begin{tabular}{ll|l} 
and Biochemistry & $\begin{array}{l}\text { DOI: 10.1159/000494875 } \\
\text { Published online: 3 November } 2018\end{array}$ & $\begin{array}{l}\text { ( } 2018 \text { The Author(s). Published by S. Karger AG, Basel } \\
\text { www.karger.com/cpb }\end{array}$ \\
\hline
\end{tabular}}

\section{Conclusion}

We identified the down-regulation of miR-30d-5p expression in NSCLC and revealed that the tumor suppressor function of miR-30d-5p might be explained by its inhibitory effect on cell growth and the regulatory network of its target genes, which are involved in specific biological process and pathways.

\section{Acknowledgements}

The study was supported by grants from the National Natural Science Foundation of China (NSFC81560469 and NSFC81360327), the Natural Science Foundation of Guangxi, China (2015GXNSFCA139009 and 2017GXNSFAA198016), Guangxi Medical University Training Program for Distinguished Young Scholars and Medical Excellence Award Funded by the Creative Research Development Grant from the First Affiliated Hospital of Guangxi Medical University and Guangxi Zhuang Autonomous Region Health and Family Planning Commission Self-financed Scientific Research project (Z20180979).

\section{Disclosure Statement}

The authors have no competing financial interests to declare.

\section{References}

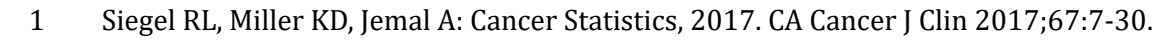

$\longrightarrow 2$ Sun LX, Li WD, Lin ZB, Duan XS, Li XF, Yang N, Lan TF, Li M, Sun Y, Yu M, Lu J: Protection against lung cancer patient plasma-induced lymphocyte suppression by Ganoderma lucidum polysaccharides. Cell Physiol Biochem 2014;33:289-299.

3 Wrangle J, Wang W, Koch A, Easwaran H, Mohammad HP, Vendetti F, Vancriekinge W, Demeyer T, Du Z, Parsana P, Rodgers K, Yen RW, Zahnow CA, Taube JM, Brahmer JR, Tykodi SS, Easton K, Carvajal RD, Jones PA, Laird PW et al.: Alterations of immune response of Non-Small Cell Lung Cancer with Azacytidine. Oncotarget 2013;4:2067-2079.

4 Roomi MW, Kalinovsky T, Niedzwiecki A, Rath M: Modulation of u-PA, MMPs and their inhibitors by a novel nutrient mixture in human lung cancer and mesothelioma cell lines. Int J Oncol 2013;42:1883-1889.

5 Travis WD, Brambilla E, Noguchi M, Nicholson AG, Geisinger K, Yatabe Y, Powell CA, Beer D, Riely G, Garg K, Austin JH, Rusch VW, Hirsch FR, Jett J, Yang PC, Gould M: International Association for the Study of Lung Cancer/American Thoracic Society/European Respiratory Society: international multidisciplinary classification of lung adenocarcinoma: executive summary. Proc Am Thorac Soc 2011;8:381-385.

6 Hou J, Meng F, Chan LW, Cho WC, Wong SC: Circulating Plasma MicroRNAs As Diagnostic Markers for NSCLC. Front Genet 2016;7:193.

7 Li W, Wang W, Ding M, Zheng X, Ma S, Wang X: MiR-1244 sensitizes the resistance of non-small cell lung cancer A549 cell to cisplatin. Cancer Cell Int 2016;16:30.

-8 Yuan Y, Li XF, Chen JQ, Dong CX, Weng SS, Huang JJ: Critical appraisal of the role of gefitinib in the management of locally advanced or metastatic non-small cell lung cancer. Onco Targets Ther 2014;7:841852.

9 Venkatesulu BP, Mallick S, Singh A, Julka PK: Non small cell carcinoma of lung with metachronous breast metastasis and cardiac tamponade: Unusual presentation of a common cancer. J Egypt Natl Canc Inst 2015;27:165-169.

10 He Y, Lin J, Kong D, Huang M, Xu C, Kim TK, Etheridge A, Luo Y, Ding Y, Wang K: Current State of Circulating MicroRNAs as Cancer Biomarkers. Clin Chem 2015;61:1138-1155.

11 Friedman RC, Farh KK, Burge CB, Bartel DP: Most mammalian mRNAs are conserved targets of microRNAs. Genome Res 2009;19:92-105. 


\section{Cellular Physiology Cell Physiol Biochem 2018;50:1964-1987 \begin{tabular}{l|l|l|l|l|}
\hline DOI: $10.1159 / 000494875$ & 2018 The Author(s). Published by S. Karger AG, Basel
\end{tabular}

12 Czochor JR, Glazer PM: microRNAs in cancer cell response to ionizing radiation. Antioxid Redox Signal 2014;21:293-312.

13 Shin VY, Chu KM: MiRNA as potential biomarkers and therapeutic targets for gastric cancer. World J Gastroenterol 2014;20:10432-10439.

14 Gambari R, Brognara E, Spandidos DA, Fabbri E: Targeting oncomiRNAs and mimicking tumor suppressor miRNAs: Nuew trends in the development of miRNA therapeutic strategies in oncology (Review). Int J Oncol 2016;49:5-32.

15 Zhou X, Ye F, Yin C, Zhuang Y, Yue G, Zhang G: The Interaction Between MiR-141 and lncRNA-H19 in Regulating Cell Proliferation and Migration in Gastric Cancer. Cell Physiol Biochem 2015;36:1440-1452.

16 Aherne ST, Madden SF, Hughes DJ, Pardini B, Naccarati A, Levy M, Vodicka P, Neary P, Dowling P, Clynes M: Circulating miRNAs miR-34a and miR-150 associated with colorectal cancer progression. BMC Cancer 2015;15:329.

17 Xu Y, Lu S: Regulation of beta-catenin-mediated esophageal cancer growth and invasion by miR-214. Am J Transl Res 2015;7:2316-2325.

18 Wu D, Pan H, Zhou Y, Zhang Z, Qu P, Zhou J, Wang W: Upregulation of microRNA-204 inhibits cell proliferation, migration and invasion in human renal cell carcinoma cells by downregulating SOX4. Mol Med Rep 2015;12:7059-7064.

19 Subramani R, Gangwani L, Nandy SB, Arumugam A, Chattopadhyay M, Lakshmanaswamy R: Emerging roles of microRNAs in pancreatic cancer diagnosis, therapy and prognosis (Review). Int J Oncol 2015;47:12031210.

20 Ma Y, Hu Q Luo W, Pratt RN, Glenn ST, Liu S, Trump DL, Johnson CS: 1alpha,25(OH)2D3 differentially regulates miRNA expression in human bladder cancer cells. J Steroid Biochem Mol Biol 2015;148:166-171.

21 Thomas J, Ohtsuka M, Pichler M, Ling H: MicroRNAs: Clinical Relevance in Colorectal Cancer. Int J Mol Sci 2015;16:28063-28076.

-22 Kumar B, Khaleghzadegan S, Mears B, Hatano K, Kudrolli TA, Chowdhury WH, Yeater DB, Ewing CM, Luo J, Isaacs WB, Marchionni L, Lupold SE: Identification of miR-30b-3p and miR-30d-5p as direct regulators of androgen receptor signaling in prostate cancer by complementary functional microRNA library screening. Oncotarget 2016; 7:72593-72607.

-23 Tarasov VA, Matishov DG, Shin EF, Boiko NV, Timoshkina NN, Makhotkin MA, Lomonosov AM, Kirpii AA, Kit OI, Maksimov AY: [Coordinated aberranit expression of miRNAs in colon cancer]. Genetika 2014;50:12321244.

24 Larsen AC: Conjunctival malignant melanoma in Denmark: Epidemiology, treatment and prognosis with special emphasis on tumorigenesis and genetic profile. Acta Ophthalmol 2016;94:842.

25 Chen D, Guo W, Qiu Z, Wang Q Li Y, Liang L, Liu L, Huang S, Zhao Y, He X: MicroRNA-30d-5p inhibits tumour cell proliferation and motility by directly targeting CCNE2 in non-small cell lung cancer. Cancer Lett 2015;362:208-217.

26 Chen WJ, Gan TQ, Qin H, Huang SN, Yang LH, Fang YY, Li ZY, Pan LJ, Chen G: Implication of downregulation and prospective pathway signaling of microRNA-375 in lung squamous cell carcinoma. Pathol Res Pract 2017;213:364-372.

-27 Butnor KJ, Beasley MB, Cagle PT, Grunberg SM, Kong FM, Marchevsky A, Okby NT, Roggli VL, Suster S, Tazelaar HD, Travis WD: Protocol for the examination of specimens from patients with primary non-small cell carcinoma, small cell carcinoma, or carcinoid tumor of the lung. Arch Pathol Lab Med 2009;133:15521559.

28 Chen G, Umelo IA, Lv S, Teugels E, Fostier K, Kronenberger P, Dewaele A, Sadones J, Geers C, De Greve J: miR-146a inhibits cell growth, cell migration and induces apoptosis in non-small cell lung cancer cells. PLoS One 2013;8:e60317.

29 Dang Y, Luo D, Rong M, Chen G: Underexpression of miR-34a in hepatocellular carcinoma and its contribution towards enhancement of proliferating inhibitory effects of agents targeting c-MET. PLoS One 2013;8:e61054.

-30 Rong M, Chen G, Dang Y: Increased miR-221 expression in hepatocellular carcinoma tissues and its role in enhancing cell growth and inhibiting apoptosis in vitro. BMC Cancer 2013;13:21.

31 Gao L, Li SH, Tian YX, Zhu QQ Chen G, Pang YY, Hu XH: Role of downregulated miR-133a-3p expression in bladder cancer: a bioinformatics study. Onco Targets Ther 2017;10:3667-3683. 


\section{Cellular Physiology Cell Physiol Biochem 2018;50:1964-1987 \begin{tabular}{l|l|l} 
and Biochemistry Published online: 3 November 2018 & $\begin{array}{l}\text { ○ } 2018 \text { The Author(s). Published by S. Karger AG, Basel } \\
\text { www.karger.com/cpb }\end{array}$ \\
\hline
\end{tabular}}

-32 Tierney JF, Stewart LA, Ghersi D, Burdett S, Sydes MR: Practical methods for incorporating summary timeto-event data into meta-analysis. Trials 2007;8:16.

33 He R, Gao L, Ma J, Peng Z, Zhou S, Yang L, Feng Z, Dang Y, Chen G: The essential role of MTDH in the progression of HCC: a study with immunohistochemistry, TCGA, meta-analysis and in vitro investigation. Am J Transl Res 2017;9:1561-1579.

34 Tang R, Zhong T, Dang Y, Zhang X, Li P, Chen G: Association between downexpression of MiR-203 and poor prognosis in non-small cell lung cancer patients. Clin Transl Oncol 2016;18:360-368.

35 Huang S, He R: Synergistic effect of MiR-146a mimic and cetuximab on hepatocellular carcinoma cells. Biomed Res Int 2014;2014:384121.

-36 Dang YW, Zeng J, He RQ Rong MH, Luo DZ, Chen G: Effects of miR-152 on cell growth inhibition, motility suppression and apoptosis induction in hepatocellular carcinoma cells. Asian Pac J Cancer Prev 2014;15:4969-4976.

-37 Nymark P, Guled M, Borze I, Faisal A, Lahti L, Salmenkivi K, Kettunen E, Anttila S, Knuutila S: Integrative analysis of microRNA, mRNA and aCGH data reveals asbestos- and histology-related changes in lung cancer. Genes Chromosomes Cancer 2011;50:585-597.

38 Wu Y, Zhang J, Hou S, Cheng Z, Yuan M: Non-small cell lung cancer: miR-30d suppresses tumor invasion and migration by directly targeting NFIB. Biotechnol Lett 2017;39:1827-1834.

39 Li C, Yin Y, Liu X, Xi X, Xue W, Qu Y: Non-small cell lung cancer associated microRNA expression signature: integrated bioinformatics analysis, validation and clinical significance. Oncotarget 2017;8:24564-24578.

40 Czubak K, Lewandowska MA, Klonowska K, Roszkowski K, Kowalewski J, Figlerowicz M, Kozlowski P: High copy number variation of cancer-related microRNA genes and frequent amplification of DICER1 and DROSHA in lung cancer. Oncotarget 2015;6:23399-23416.

41 Guo J, Meng R, Yin Z, Li P, Zhou R, Zhang S, Dong X, Liu L, Wu G: A serum microRNA signature as a prognostic factor for patients with advanced NSCLC and its association with tissue microRNA expression profiles. Mol Med Rep 2016;13:4643-4653.

42 Hu Z, Chen X, Zhao Y, Tian T, Jin G, Shu Y, Chen Y, Xu L, Zen K, Zhang C, Shen H: Serum microRNA signatures identified in a genome-wide serum microRNA expression profiling predict survival of non-small-cell lung cancer. J Clin Oncol 2010;28:1721-1726.

43 Lin Q, Mao W, Shu Y, Lin F, Liu S, Shen H, Gao W, Li S, Shen D: A cluster of specified microRNAs in peripheral blood as biomarkers for metastatic non-small-cell lung cancer by stem-loop RT-PCR. J Cancer Res Clin Oncol 2012;138:85-93.

44 Chen X, Ba Y, Ma L, Cai X, Yin Y, Wang K, Guo J, Zhang Y, Chen J, Guo X, Li Q Li X, Wang W, Zhang Y, Wang J, Jiang X, Xiang Y, Xu C, Zheng P, Zhang J, Li R, Zhang H, Shang X, Gong T, Ning G, Wang J, Zen K, Zhang J, Zhang CY: Characterization of microRNAs in serum: a novel class of biomarkers for diagnosis of cancer and other diseases. Cell Res 2008;18:997-1006.

45 Ohyashiki K, Umezu T, Yoshizawa S, Ito Y, Ohyashiki M, Kawashima H, Tanaka M, Kuroda M, Ohyashiki JH: Clinical impact of down-regulated plasma miR-92a levels in non-Hodgkin's lymphoma. PLoS One 2011;6:e16408.

46 Shigoka M, Tsuchida A, Matsudo T, Nagakawa Y, Saito H, Suzuki Y, Aoki T, Murakami Y, Toyoda H, Kumada T, Bartenschlager R, Kato N, Ikeda M, Takashina T, Tanaka M, Suzuki R, Oikawa K, Takanashi M, Kuroda M: Deregulation of miR-92a expression is implicated in hepatocellular carcinoma development. Pathol Int 2010;60:351-357.

47 Tanaka M, Oikawa K, Takanashi M, Kudo M, Ohyashiki J, Ohyashiki K, Kuroda M: Down-regulation of miR-92 in human plasma is a novel marker for acute leukemia patients. PLoS One 2009;4:e5532.

48 Song Y, Song C, Yang S: Tumor-Suppressive Function of miR-30d-5p in Prostate Cancer Cell Proliferation and Migration by Targeting NT5E. Cancer Biother Radiopharm 2018;33:203-211.

49 Yan L, Qiu J, Yao J: Downregulation of microRNA-30d promotes cell proliferation and invasion by targeting LRH-1 in colorectal carcinoma. Int J Mol Med 2017;39:1371-1380.

50 Xie R, Wu SN, Gao CC, Yang XZ, Wang HG, Zhang JL, Yan W, Ma TH: MicroRNA-30d inhibits the migration and invasion of human esophageal squamous cell carcinoma cells via the posttranscriptional regulation of enhancer of zeste homolog 2. Oncol Rep 2017;37:1682-1690.

51 Bergstrom KS, Xia L: Mucin-type 0-glycans and their roles in intestinal homeostasis. Glycobiology 2013;23:1026-1037. 


\section{Cellular Physiology Cell Physiol Biochem 2018;50:1964-1987 \begin{tabular}{l|l|l|l|}
\hline DOI: 10.1159/000494875 & 2018 The Author(s). Published by S. Karger AG, Basel
\end{tabular}

52 Hooper LV, Gordon JI: Glycans as legislators of host-microbial interactions: spanning the spectrum from symbiosis to pathogenicity. Glycobiology 2001;11:1r-10r.

53 Sonnenburg JL, Angenent LT, Gordon JI: Getting a grip on things: how do communities of bacterial symbionts become established in our intestine? Nat Immunol 2004;5:569-573.

-54 van der Post S, Subramani DB, Backstrom M, Johansson ME, Vester-Christensen MB, Mandel U, Bennett EP, Clausen H, Dahlen G, Sroka A, Potempa J, Hansson GC: Site-specific 0-glycosylation on the MUC2 mucin protein inhibits cleavage by the Porphyromonas gingivalis secreted cysteine protease (RgpB). J Biol Chem 2013;288:14636-14646.

-55 Hanahan D, Weinberg RA: Hallmarks of cancer: the next generation. Cell 2011;144:646-674.

56 Hoffman RM: Altered methionine metabolism, DNA methylation and oncogene expression in carcinogenesis. A review and synthesis. Biochim Biophys Acta 1984;738:49-87.

57 Guo HY, Herrera H, Groce A, Hoffman RM: Expression of the biochemical defect of methionine dependence in fresh patient tumors in primary histoculture. Cancer Res 1993;53:2479-2483.

58 Guo H, Lishko VK, Herrera H, Groce A, Kubota T, Hoffman RM: Therapeutic tumor-specific cell cycle block induced by methionine starvation in vivo. Cancer Res 1993;53:5676-5679.

59 Al-Awadi F, Yang M, Tan Y, Han Q, Li S, Hoffman RM: Human tumor growth in nude mice is associated with decreased plasma cysteine and homocysteine. Anticancer Res 2008;28:2541-2544.

60 Cho NH, Choi YP, Moon DS, Kim H, Kang S, Ding O, Rha SY, Yang YJ, Cho SH: Induction of cell apoptosis in non-small cell lung cancer cells by cyclin A1 small interfering RNA. Cancer Sci 2006;97:1082-1092.

61 Su L, Han D, Wu J, Huo X: Skp2 regulates non-small cell lung cancer cell growth by Meg3 and miR-3163. Tumour Biol 2016;37:3925-3931.

62 Li L, Liu H, Du L, Xi P, Wang Q, Li Y, Liu D: MiR-449a Suppresses LDHA-Mediated Glycolysis to Enhance the Sensitivity of Non-Small Cell Lung Cancer Cells to Ionizing Radiation. Oncol Res 2017. doi: 10.3727/096504 $017 X 15016337254605$.

63 Zhu X, Li Y, Shen H, Li H, Long L, Hui L, Xu W: miR-137 inhibits the proliferation of lung cancer cells by targeting Cdc42 and Cdk6. FEBS Lett 2013;587:73-81.

64 Liu X, Qu L: Gene expression-signatures for non-small cell lung cancer patients with different EGFR muational status. https://www.ncbi.nlm.nih.gov/geo/query/acc.cgi?acc=GSE93300.

65 Keller A, Leidinger P, Borries A, Wendschlag A, Wucherpfennig F, Scheffler M, Huwer H, Lenhof HP, Meese E: miRNAs in lung cancer - studying complex fingerprints in patient's blood cells by microarray experiments. BMC Cancer 2009;9:353.

66 Patnaik SK, Yendamuri S, Kannisto E, Kucharczuk JC, Singhal S, Vachani A: MicroRNA expression profiles of whole blood in lung adenocarcinoma. PLoS One 2012;7:e46045.

67 Keller A, Leidinger P, Bauer A, Elsharawy A, Haas J, Backes C, Wendschlag A, Giese N, Tjaden C, Ott K, Werner J, Hackert T, Ruprecht K, Huwer H, Huebers J, Jacobs G, Rosenstiel P, Dommisch H, Schaefer A, Muller-Quernheim J, Wullich B, Keck B, Graf N, Reichrath J, Vogel B, Nebel A, Jager SU, Staehler P, Amarantos I, Boisguerin V, Staehler C, Beier M, Scheffler M, Buchler MW, Wischhusen J, Haeusler SF, Dietl J, Hofmann S, Lenhof HP, Schreiber S, Katus HA, Rottbauer W, Meder B, Hoheisel JD, Franke A, Meese E: Toward the bloodborne miRNome of human diseases. Nat Methods 2011;8:841-843.

-68 Patnaik SK, Kannisto ED, Mallick R, Vachani A, Yendamuri S: Whole blood microRNA expression may not be useful for screening non-small cell lung cancer. PLoS One 2017;12:e0181926.

69 Godrey A, Xu Z, Sieber S, Hayes N, Rivera P, Taylor J: Serum miRNA expression is associated with lung cancer in a case-control study and normalizes following surgical resection. https://www.ncbi.nlm.nih.gov/ geo/query/acc.cgi?acc=GSE46729.

70 Keller A, Leidinger P, Vogel B, Backes C, ElSharawy A, Galata V, Mueller SC, Marquart S, Schrauder MG, Strick R, Bauer A, Wischhusen J, Beier M, Kohlhaas J, Katus HA, Hoheisel J, Franke A, Meder B, Meese E: miRNAs can be generally associated with human pathologies as exemplified for miR-144. BMC Med 2014;12:224.

71 Leidinger P, Galata V, Backes C, Stahler C, Rheinheimer S, Huwer H, Meese E, Keller A: Longitudinal study on circulating miRNAs in patients after lung cancer resection. Oncotarget 2015;6:16674-16685.

72 Lodes MJ, Caraballo M, Suciu D, Munro S, Kumar A, Anderson B: Detection of cancer with serum miRNAs on an oligonucleotide microarray. PLoS One 2009;4:e6229.

73 Tan X, Qin W, Zhang L, Hang J, Li B, Zhang C, Wan J, Zhou F, Shao K, Sun Y, Wu J, Zhang X, Qiu B, Li N, Shi S, Feng X, Zhao S, Wang Z, Zhao X, Chen Z, Mitchelson K, Cheng J, Guo Y, He J: A 5-microRNA signature for lung squamous cell carcinoma diagnosis and hsa-miR-31 for prognosis. Clin Cancer Res 2011;17:6802-6811. 


\section{Cellular Physiology Cell Physiol Biochem 2018:50:1964-1987

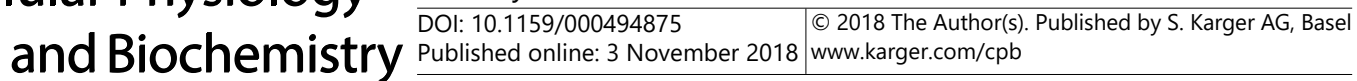 \\ Gao et al.: miR-30d-5p: Expression Signature and Tumor Suppressive Role in NSCLC}

74 Raponi M, Dossey L, Jatkoe T, Wu X, Chen G, Fan H, Beer DG: MicroRNA classifiers for predicting prognosis of squamous cell lung cancer. Cancer Res 2009;69:5776-5783.

75 Ohba T, Nagano H: A small-cell lung cancer subtype with good prognosis found by a three miRNA signature. https://www.ncbi.nlm.nih.gov/geo/query/acc.cgi?acc=GSE19945.

76 van Jaarsveld MT, Wouters MD, Boersma AW, Smid M, van Ijcken WF, Mathijssen RH, Hoeijmakers JH, Martens JW, van Laere S, Wiemer EA, Pothof J: DNA damage responsive microRNAs misexpressed in human cancer modulate therapy sensitivity. Mol Oncol 2014;8:458-468.

77 Bjaanaes MM, Halvorsen AR, Solberg S, Jorgensen L, Dragani TA, Galvan A, Colombo F, Anderlini M, Pastorino U, Kure E, Borresen-Dale AL, Brustugun OT, Helland A: Unique microRNA-profiles in EGFRmutated lung adenocarcinomas. Int J Cancer 2014;135:1812-1821.

-78 Tai MC, Kajino T, Nakatochi M, Arima C, Shimada Y, Suzuki M, Miyoshi H, Yatabe Y, Yanagisawa K, Takahashi T: miR-342-3p regulates MYC transcriptional activity via direct repression of E2F1 in human lung cancer. Carcinogenesis 2015;36:1464-1473.

79 Robles AI, Arai E, Mathe EA, Okayama H, Schetter AJ, Brown D, Petersen D, Bowman ED, Noro R, Welsh JA, Edelman DC, Stevenson HS, Wang Y, Tsuchiya N, Kohno T, Skaug V, Mollerup S, Haugen A, Meltzer PS, Yokota J, Kanai Y, Harris CC: An Integrated Prognostic Classifier for Stage I Lung Adenocarcinoma Based on mRNA, microRNA, and DNA Methylation Biomarkers. J Thorac Oncol 2015;10:1037-1048.

80 Gasparini P, Cascione L, Landi L, Carasi S, Lovat F, Tibaldi C, Ali G, D’Incecco A, Minuti G, Chella A, Fontanini G, Fassan M, Cappuzzo F, Croce CM: microRNA classifiers are powerful diagnostic/prognostic tools in ALK-, EGFR-, and KRAS-driven lung cancers. Proc Natl Acad Sci U S A 2015;112:14924-14929.

81 Jin Y, Liu YL, Lu SH: The miRNA expression profiles in three subtypes of lung carcinomas. https://www. ncbi.nlm.nih.gov/geo/query/acc.cgi?acc=GSE74190.

82 Yoshimoto T, Motoi N, Yamamoto N, Nagano H, Ushijima M, Matsuura M, Okumura S, Yamaguchi T, Fukayama M, Ishikawa Y: Pulmonary Carcinoids and Low-Grade Gastrointestinal Neuroendocrine Tumors Show Common MicroRNA Expression Profiles, Different from Adenocarcinomas and Small Cell Carcinomas. Neuroendocrinology 2018;106:47-57.

-83 Lu J, Getz G, Miska EA, Alvarez-Saavedra E, Lamb J, Peck D, Sweet-Cordero A, Ebert BL, Mak RH, Ferrando AA, Downing JR, Jacks T, Horvitz HR, Golub TR: MicroRNA expression profiles classify human cancers. Nature 2005;435:834-838.

84 Ma L, Huang Y, Zhu W, Zhou S, Zhou J, Zeng F, Liu X, Zhang Y, Yu J: An integrated analysis of miRNA and mRNA expressions in non-small cell lung cancers. PLoS One 2011;6:e26502.

-85 Fujita Y, Yagishita S, Hagiwara K, Yoshioka Y, Kosaka N, Takeshita F, Fujiwara T, Tsuta K, Nokihara H, Tamura T, Asamura H, Kawaishi M, Kuwano K, Ochiya T: The clinical relevance of the miR-197/CKS1B/STAT3mediated PD-L1 network in chemoresistant non-small-cell lung cancer. Mol Ther 2015;23:717-727. 